San Jose State University

SJSU ScholarWorks

Master's Theses

Master's Theses and Graduate Research

1997

\title{
Study of the folding-unfolding equilibrium of ribonuclease $A$ by microcolumn techniques
}

Sharmila Udiavar

San Jose State University

Follow this and additional works at: https://scholarworks.sjsu.edu/etd_theses

\section{Recommended Citation}

Udiavar, Sharmila, "Study of the folding-unfolding equilibrium of ribonuclease A by microcolumn techniques" (1997). Master's Theses. 1608.

DOI: https://doi.org/10.31979/etd.umzx-72sf

https://scholarworks.sjsu.edu/etd_theses/1608

This Thesis is brought to you for free and open access by the Master's Theses and Graduate Research at SJSU ScholarWorks. It has been accepted for inclusion in Master's Theses by an authorized administrator of SJSU ScholarWorks. For more information, please contact scholarworks@sjsu.edu. 


\section{INFORMATION TO USERS}

This manuscript has been reproduced from the microfilm master. UMI films the text directly from the original or copy submitted. Thus, some thesis and dissertation copies are in typewriter face, while others may be from any type of computer printer.

The quality of this reproduction is dependent upon the quality of the copy submitted. Broken or indistinct print, colored or poor quality illustrations and photographs, print bleedthrough, substandard margins, and improper alignment can adversely affect reproduction.

In the unlikely event that the author did not send UMI a complete manuscript and there are missing pages, these will be noted. Also, if unauthorized copyright material had to be removed, a note will indicate the deletion.

Oversize materials (e.g., maps, drawings, charts) are reproduced by sectioning the original, beginning at the upper left-hand comer and continuing from left to right in equal sections with small overlaps. Each original is also photographed in one exposure and is included in reduced form at the back of the book.

Photographs included in the original manuscript have been reproduced xerographically in this copy. Higher quality 6" $\times 9$ " black and white photographic prints are available for any photographs or illustrations appearing in this copy for an additional charge. Contact UMI directly to order.

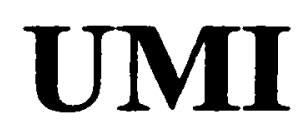

A Bell \& Howell Information Company 300 North Zeeb Road. Ann Arbor MI 48106-1346 USA 



\title{
STUDY OF THE FOLDING-UNFOLDING EQUILIBRIUM
}

OF

RIBONUCLEASE A

BY

\section{MICROCOLUMN TECHNIQUES}

\author{
A Thesis \\ Presented to \\ The Faculty of the Department of Chemistry \\ San Jose State University \\ In Partial Fulfillment \\ of the Requirements for the Degree \\ Master of Science
}

by

Sharmila Udiavar

December 1997 
UMI Number: 1388226

UMI Microform 1388226

Copyright 1998, by UMI Company. All rights reserved.

This microform edition is protected against unauthorized copying under Title 17, United States Code.

\section{UMI}

300 North Zeeb Road

Ann Arbor, MI 48103 
(c) 1997

Sharmila Udiavar

ALL RIGHTS RESERVED 


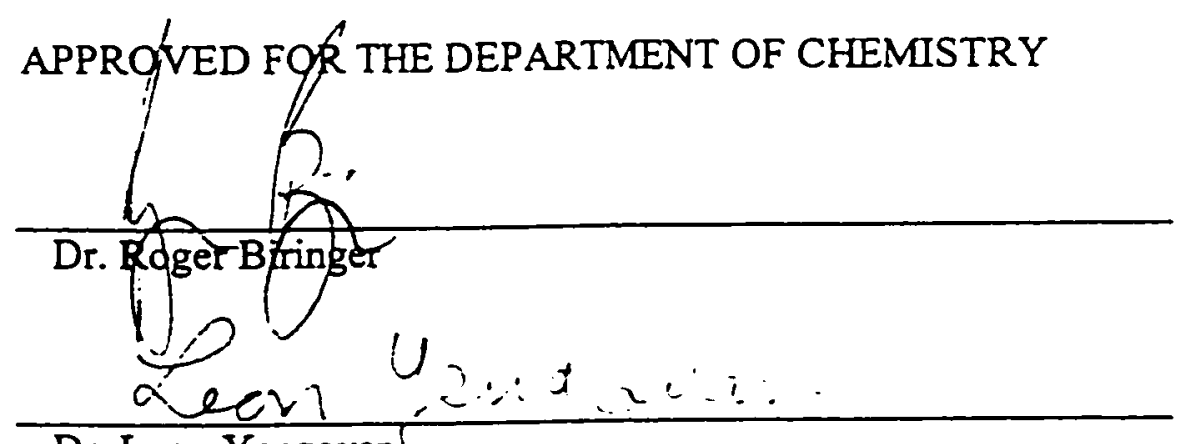

Dr. Leon Yengoyan

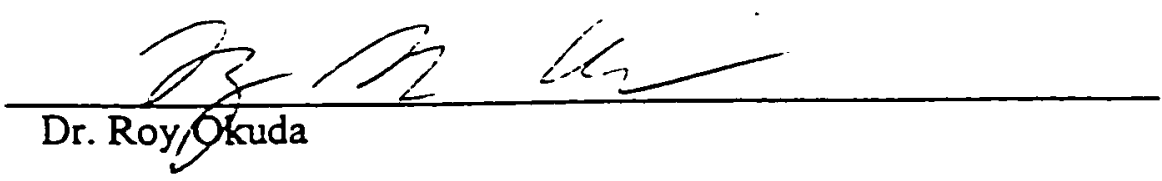

APPROVED FOR THE UNIVERSITY

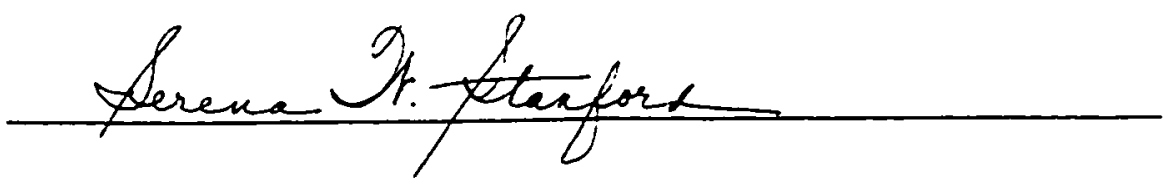




\title{
ABSTRACT \\ STUDY OF THE FOLDING-UNFOLDING EQUILIBRIUM OF RIBONUCLEASE A BY MICROCOLUMN TECHNIQUES
}

\author{
by Sharmila Udiavar
}

Proteins fold spontaneously into their functional native conformation. Considerable research has been conducted to study the nature and magnitude of the forces that determine their conformation and stabilize the native structure. The mechanism by which proteins fold into the native conformation is still uncertain.

We have have examined the thermal unfolding of RNase $A$ by using Capillary Zone Electrophoresis, UV absorbance and the Taylor-Aris Diffusion method. Unfolding of RNase $\mathrm{A}$ was observed at $\mathrm{pH}$ values of 3.00 and 4.5. The transition midpoint as obtained by all techniques increases as the $\mathrm{pH}$ of the buffer solution increases. At $\mathrm{pH}$ 3.00, all the methods show a major transition at $43-45^{\circ} \mathrm{C}$. Along with the major transition, the mobility data shows an indication of a pretransition, whereas a posttransition is indicated at $48{ }^{\circ} \mathrm{C}$ by both the mobility and diffusion data. At $\mathrm{pH} 4.50$. all the methods show a major transition at $50-51^{\circ} \mathrm{C}$ with no posttransition. The mobility and absorbance data indicate the presence of a pretransition at $38-40{ }^{\circ} \mathrm{C}$. Finally, the above findings are compared with previous protein folding studies. 


\section{ACKNOWLEDGMENTS}

Influence for this work has come from many comers. I would like to begin by expressing my deepest gratitude to Dr. Roger Biringer for the invaluable guidance that he has provided to me during the entire course of this thesis. I would also like to offer my thanks to Dr. Leon Yengoyan who had faith in my abilities and to Dr. Roy Okuda for his constructive feedback on my thesis.

Some of my team members at Hewlett-Packard Laboratories deserve special mention. To Dr. William Hancock who mentored me and who was always there with support and encouragement, I would like to say a heartfelt "thank you". I am indebted to Dr. Sally Swedberg who showed me how to enjoy and appreciate the numerous little things that go into a successful research project.

I owe special thanks to my family. My parents for their motivation during my school years and my in-laws whose enthusiasm and support inspired me to reach greater heights. Finally, this thesis could never have been done if not for the faithful and loving support of my husband Nandan, and my son Akshay who made it all worthwhile in his own special way. 


\section{TABLE OF CONTENTS}

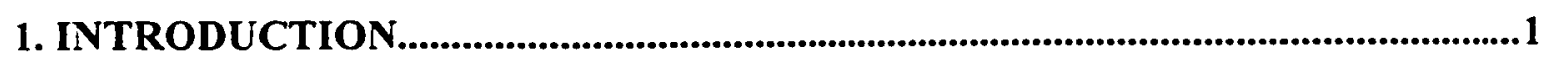

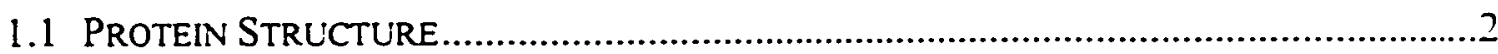

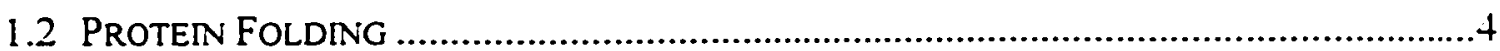

1.2.1 What is the Protein Folding Problem? An Introduction ..................................

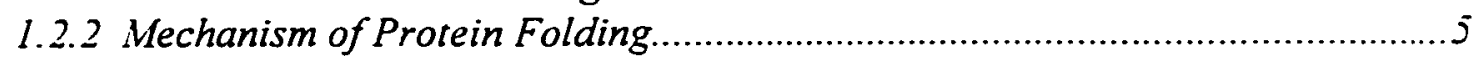

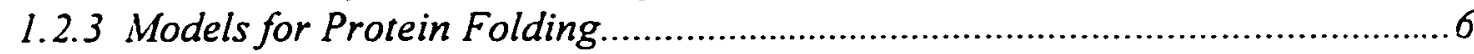

1.2.3.1 Nucleation, Rapid-Growth Model …....................................................6

1.2.3.2 Jigsaw-puzzle Model ..........................................................................

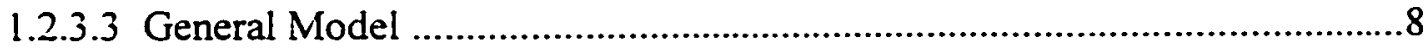

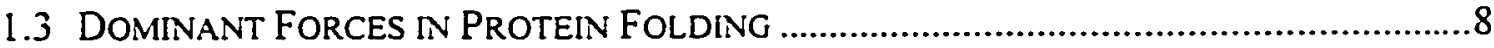

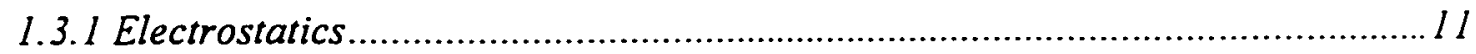

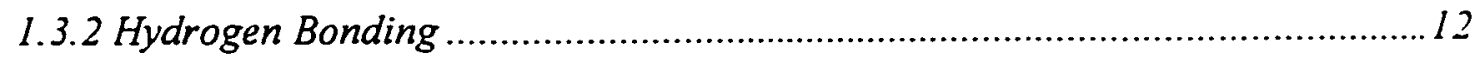

1.3.3 Hydrophobic Interaction ......................................................................... It

1.4 BASIC TECHNIQUES FOR MONITORING PROTEIN FOLDING ......................................14

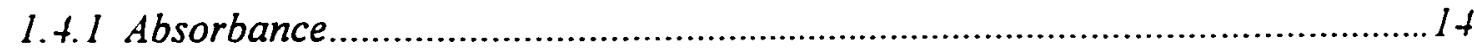

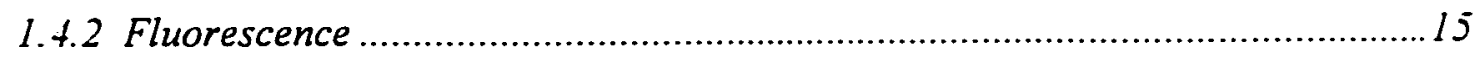

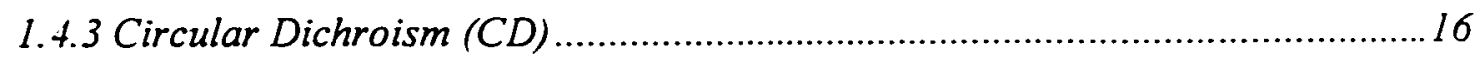

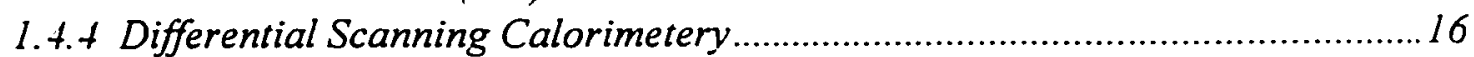

1.4.5 Electrophoresis................................................................................. 7

1.5 EQUILIBRIUM METHOD FOR UNFOLdING AND REFOLDING OF PROTEINS ..................... 17

1.6 HIGH PERFormanCE CAPILLARY ElECTROPHORESIS (HPCE) ..............................26

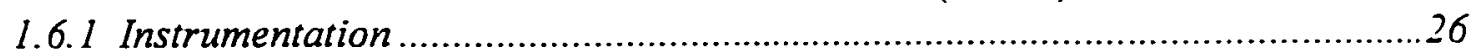

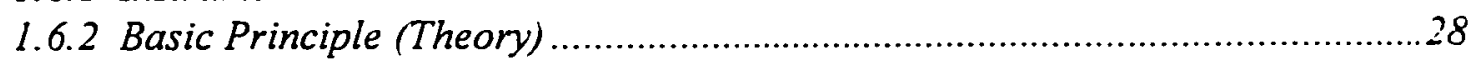

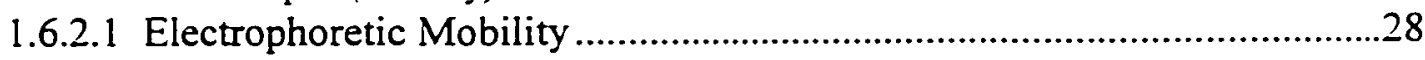

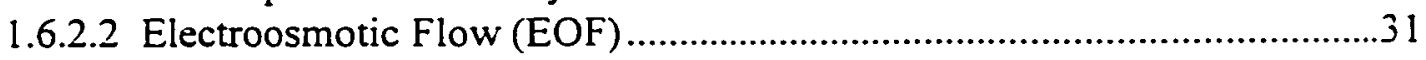

1.6.3 Capillary Zone Electrophoresis (CZE) ..................................................... $3+$

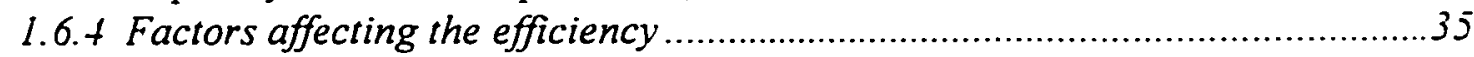

1.6.4.1 Joule Heating Effect and Temperature Gradient........................................35

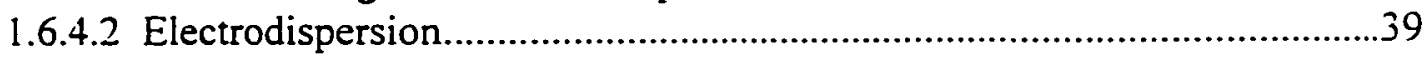

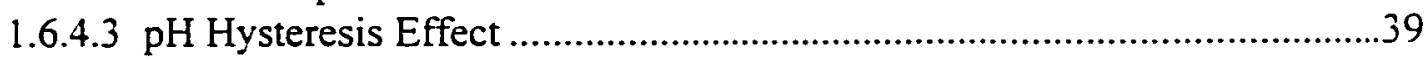

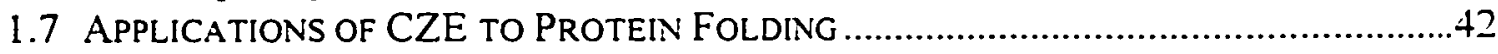

1.7.1 Temperature Study ...................................................................................

1.7.1.1 Temperature Effect on the Electrophoretic Behavior ...............................4

1.7.1.2. Thermally induced protein folding / unfolding transition using free solution capillary electrophoresis (FSCE) …....................................................................4

1.8 APPLICATION OF THE DIFFUSION METHOD TO STUDY OF PROTEIN FOLDING ................47

1.8.2 Application of the Taylor-Aris method to protein folding.................................5t

1.8.3 Using a combination of electrophoretic mobility and diffusion measurements in the study of protein folding 


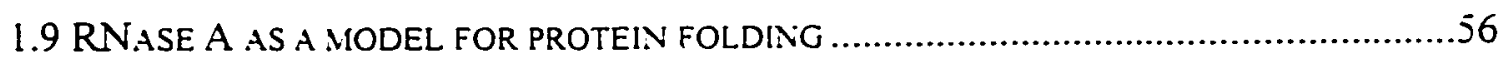

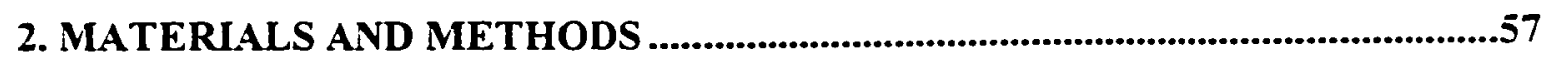

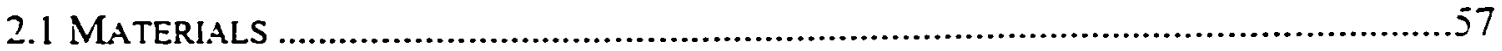

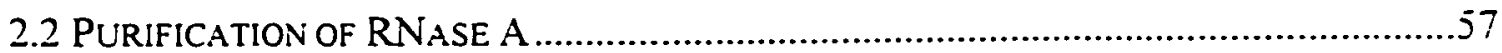

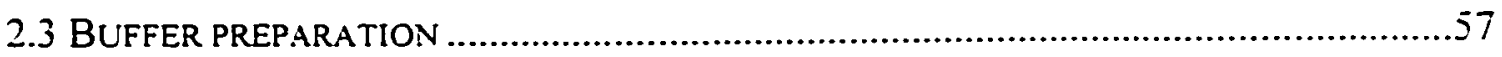

2.3.1 Preparation of formate buffer .........................................................................

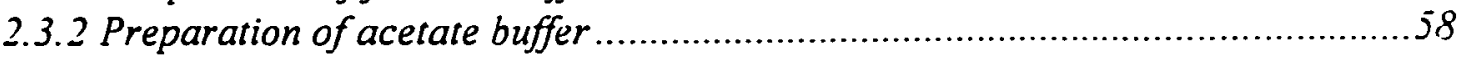

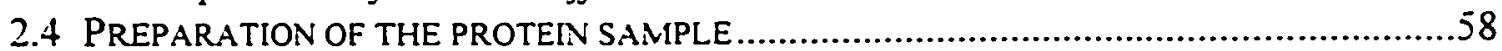

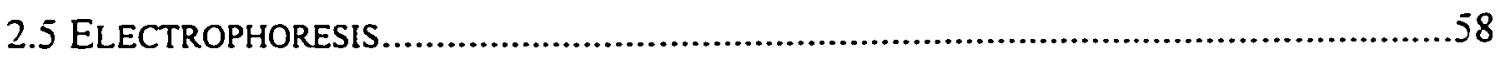

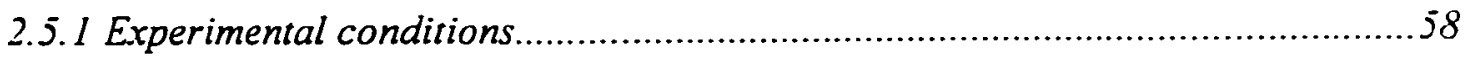

2.5.2 Calculation of the injected sample volume ................................................60

2.5.3 Calculations for the mobility of RVase $A$ at a particular temperature.............61

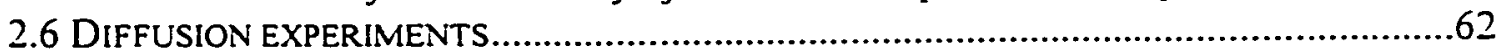

2.6.1 Experimental conditions............................................................................62

2.6.2 Diffusion coefficient calculations for RNase At with Taylor-Aris Dispersion

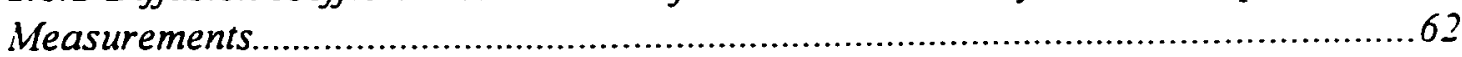

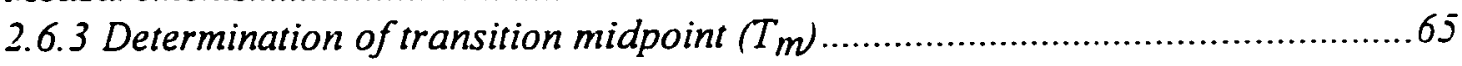

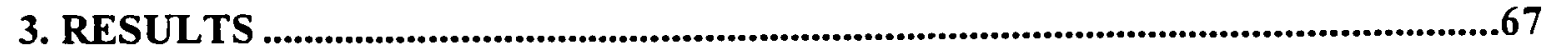

3.1 THERMAL DENATURATION OF RNASE A ................................................................67

3.1.1 Examination of the denaturation of RNase A monitored by electrophoretic mobility and absorbance using formate buffer at $\mathrm{pH} 3.00$....................................6 7 3.1.2 Examination of the denaturation of RNase A by Taylor-Aris Diffusion Method

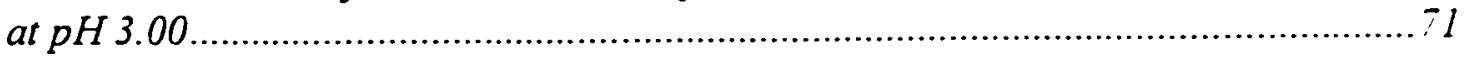

3.1.3 Examination of the denaturation of RNase $A$ by electrophoresis and absorbance at $\mathrm{pH}+.5$ with acetate buffer............................................................................ I

3.1. + Examination of the denaturation of RNase $A$ by the Taylor-Aris dispersion

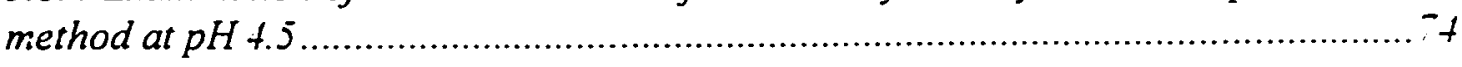

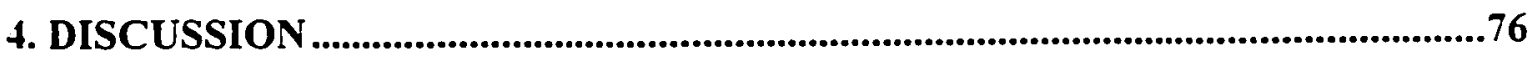

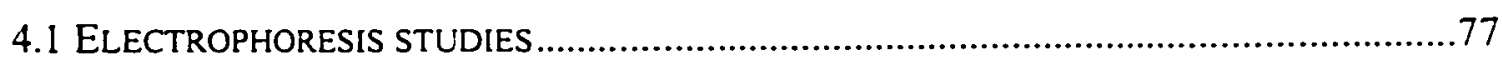

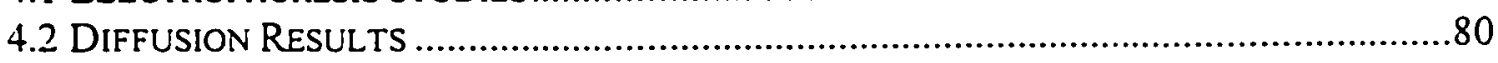

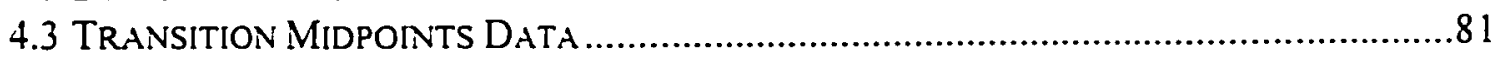

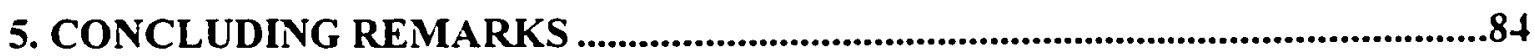

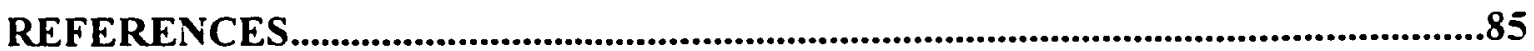




\section{LIST OF TABLES}

Table I: Comparison of FSCE and DSC .49

Table II: Comparision of Transition midpoints by various methods.

.68 


\section{LIST OF FIGURES}

Figure 1: Three dimensional structure of a protein ........................................................

Figure 2: Nucleation rapid-growth model...............................................................

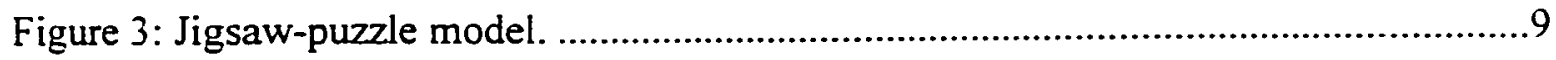

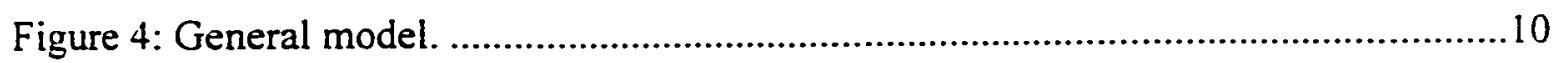

Figure 5: Typical hydrogen bonds in proteins. ........................................................ 13

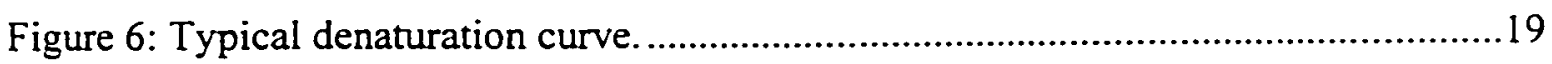

Figure 7: $\Delta \mathrm{G}\left(\mathrm{H}_{2} \mathrm{O}\right)$ as a fuction of the unfolding of RNase $A(A)$ or $R$ Nase $T_{1}(B) \ldots \ldots \ldots . .21$

Figure 8: The thermal denaturation of ribonuclease at several $\mathrm{pH}$ values at 0.16 ionic strength, followed by difference absorption measurement ...........................................23

Figure 9: The reduced viscosity of ribonuclease in a $\mathrm{SO}_{4}{ }^{2-}-\mathrm{HSO}_{4}$ buffer at $\mathrm{pH} 2.1$ and 0.019 ionic strengths as a function of temperature

Figure 10: Alkylurea studies. Denaturation profile of RNase A using a variety of alkylureas at $\mathrm{pH}^{*} 4.00$ and $17^{\circ} \mathrm{C}$ as monitored by the intrinsic fluorescence $(280 / 350$ $\mathrm{nm})$. Raw data was standardized by conversion to fraction of unfolded molecules..........25

Figure 11: HPCE Instrumentation .27

Figure 12: Differential solute migration superimposed on electroosmotic flow in CZE...30

Figure 13: Representation of the double layer at the capillary wall ..............................32

Figure 14: Development of the electroosmotic flow ................................................. 33

Figure 15: Effect of Joule heating and temperature gradients on solute zone deformation

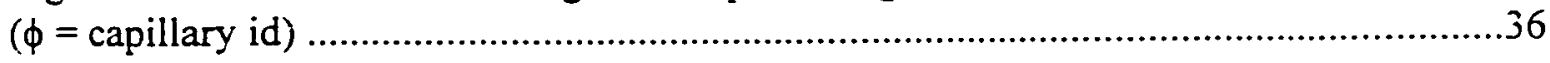

Figure 16: Temperature gradients from capillary center to the surrounding .....................38

Figure 17: Methods to control Joule heating ...........................................................

Figure 18: Electrodispersion due to mismatched sample and buffer conductivities...........1

Figure 19: Effect of the electrophoretic mobility in silica capillary (ionic strength 0.01).43 
Figure 20: Electropherograms of horse heart myoglobin $(0.2 \mathrm{mg} / \mathrm{ml})$ at $20,30,45,40.45$ and $50{ }^{\circ} \mathrm{C}$ (ascending order) at a field of $350 \mathrm{~V} / \mathrm{cm}$

Figure 21: Comparison of the influence of temperature on the electrophoretic behavior of $\alpha$-lactalbumin $(0.2 \mathrm{mg} / \mathrm{ml})$ at $20,30,35,40,45$ and $50^{\circ} \mathrm{C}$ (ascending direction ) at a field of $350 \mathrm{~V} / \mathrm{cm}$

Figure 22: Electrophoretic mobility values obtained at various temperatures for the peptide standard RKRSRKE (closed triangles) and lysozyme (closed circles).

Figure 23: Capillary electropherograms of lysozyme at (A) $37^{\circ} \mathrm{C}$, (B) $42^{\circ} \mathrm{C}$, (C) $47^{\circ} \mathrm{C}$. (D) $52{ }^{\circ} \mathrm{C},(\mathrm{E}) 57^{\circ} \mathrm{C},(\mathrm{F}) 62^{\circ} \mathrm{C}$, and (G) $67^{\circ} \mathrm{C}$. The first peak corresponds to the peptide mobility standard (RKRSRKE) and the second peak is lysozyme

Figure 24: Thermal denaturation of $\mathrm{RNase} A$ at $\mathrm{pH} 3.00$ with the help of absorbance method. Conditions: buffer used $10 \mathrm{mM}$ formate and $100 \mathrm{mM} \mathrm{KCl}, 1=57 \mathrm{~cm} . \mathrm{L}=65.5$ $\mathrm{cm}$, capillary id $=50 \mu \mathrm{m}$.

Figure 25: Thermal denaturation of RNase $\mathrm{A}$ at $\mathrm{pH} 3.00$ with the help of electrophoretic mobility. Conditions: buffer used $10 \mathrm{mM}$ formate and $100 \mathrm{mM} \mathrm{KCl}, \mathrm{l}=57 \mathrm{~cm}, \mathrm{~L}=65.5$ $\mathrm{cm}$, capillary id $=50 \mu \mathrm{m}$.

Figure 26: Thermal denaturation of $\mathrm{RNase} A$ at $\mathrm{pH} 3.00$ with the help of diffusion coefficient method. Conditions: buffer used $10 \mathrm{mM}$ formate and $100 \mathrm{mM} \mathrm{KCl}, \mathrm{l}=57 \mathrm{~cm}$. $\mathrm{L}=65.5 \mathrm{~cm}$, capillary id $=50 \mu \mathrm{m}$.

Figure 27: Thermal denaturation of $\mathrm{RNase} \mathrm{A}$ at $\mathrm{pH} 4.50$ with the help of absorbance method. Conditions: buffer used $10 \mathrm{mM}$ acetate and $100 \mathrm{mM} \mathrm{KCl}, \mathrm{l}=57 \mathrm{~cm}, \mathrm{~L}=65.5$ $\mathrm{cm}$, capillary id $=50 \mu \mathrm{m}$.

Figure 28: Thermal denaturation of $\mathrm{RNase} A$ at $\mathrm{pH} 4.50$ with the help of electrophoretic mobility. Conditions: buffer used $10 \mathrm{mM}$ acetate and $100 \mathrm{mM} \mathrm{KCl}, \mathrm{l}=57 \mathrm{~cm}, \mathrm{~L}=65.5$ $\mathrm{cm}$, capillary id $=50 \mu \mathrm{m}$.

Figure 29: Thermal denaturation of $\mathrm{RNase} A$ at $\mathrm{pH}+.50$ with the help of diffusion coefficient method. Conditions: buffer used $10 \mathrm{mM}$ acetate and $100 \mathrm{mM} \mathrm{KCl}, 1=57 \mathrm{~cm}$. $\mathrm{L}=65.5 \mathrm{~cm}$, capillary id $=50 \mu \mathrm{m}$.

Figure 30: Urea-gradient gel electrophoresis of native and reduced carboxymethylated ribonuclease 


\section{INTRODUCTION}

The three-dimensional structure of a protein consists of primary, secondary and tertiary structures. The primary structure, which is the sequence of amino acids along the polypeptide chain, forms the secondary structure which in turn forms the tertiary structure. This compact tertiary structure is the native, biologically competent structure of the protein and most proteins fold spontaneously into their particular native conformation. Considerable research has been carried out to determine the nature and magnitude of the forces that stabilize the native structure and to study the folding pathway for proteins.

The information for determining the three-dimensional structure of a protein is carried entirely in the amino acid sequence of the protein. The folding process is driven mainly by a hydrophobic effect. In the folding process, the non-polar residues in the protein coalesce to form a hydrophobic core and the polar residues arrange themselves surrounding this core. The structure is also stabilized by hydrogen bonding and ion pairing. For many proteins, the folding process goes through one or more intermediate structures either randomly or sequentially to attain a native folded structure. The folding pathway has been studied extensively by using various denaturants such as temperature and urea.

When extreme conditions such as a change in temperature or the addition of a denaturant like urea is used, the protein loses its compact native structure to form a random coil. Protein folding can be studied by making an incremental change in the concentration of the denaturant to cause a partial unfolding of the protein. The folded and 
unfolded states are quantitated to determine the extent of the folding. Some proteins display a sharp change between the folded and unfolded states indicating a two-state (native and denatured) transition while other proteins show multistate transitions with two or more intermediate states.

Various techniques such as absorbance, fluorescence, circular dichroism and calorimetery have been employed for studying the folding of proteins. Capillary zone electrophoresis (CZE) is a newly developed alternative method for studying the folding/unfolding transition. The main principle behind the method is that the mobility of the charged protein depends upon its charge/shape ratio. As the protein denatures, its compact structure undergoes expansion during which different amino acids are exposed to the solvent causing a change in the size and the net charge of the protein and, consequently, in the mobility of the protein. This method can be applied to both thermal and chemical denaturation studies.

The purpose of this project is to explore the feasibility of applying CZE to examine protein folding. Many papers have been published regarding protein separation by CZE, but few have addressed protein folding. Before considering the application of CZE to protein folding, it is important to examine what is known about the folding process and the basic principle behind the CZE techniques.

\subsection{Protein Structure}

As shown in Figure 1, protein structure can be divided into four levels. The primary structure is the sequence of amino acids that are connected to each other by peptide 


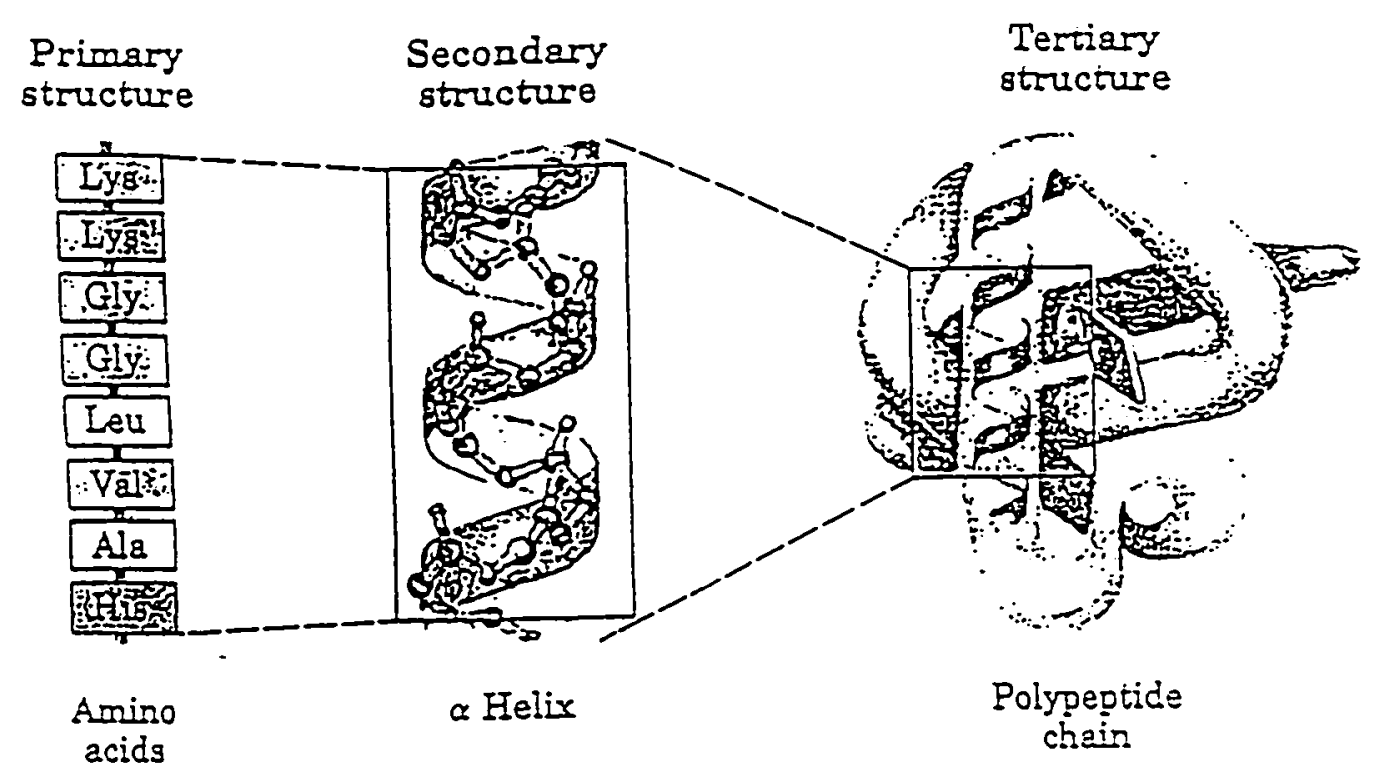

Figure 1: Three dimensional structure of a protein (reproduced with permission from Lehninger, A. L.; Nelson, D. L.; Cox, M. M. Principles of Biochemistry; Worth: New York, 1993; p 161). 
bonds. The free rotation about the $\phi$ and $\psi$ angles between the amino acids allows the polypeptide chain to fold back onto itself into regular repeating structures known collectively as the secondary structure. This secondary structure is stabilized mainly by hydrogen bonds. Some common types of the secondary structure are the $\alpha$ helix, $\beta$ sheet. turns and coils. The spatial arrangement of these secondary units in the folded protein is known as the tertiary structure.'

\subsection{Protein Folding}

\subsubsection{What is the Protein Folding Problem? An Introduction}

Proteins are macromolecules with a non-repetitive, specific covalent structure and can adopt a specific three-dimensional structure or conformation. Anfinsen demonstrated that most proteins fold spontaneously into their functional native conformation. ${ }^{2}$ Protein folding is the process by which a random polypeptide chain folds onto itself to form a biologically active three-dimensional structure. To be biologically active, all proteins must adopt a specific folded three-dimensional structure. It has been observed that proteins with a given amino acid sequence always attain the same native structure and that different amino acid sequences result in different native structures indicating that the amino acid sequence "codes" for the native protein structure. The protein folding problem involves deciphering this "code". The solution to the protein folding problem requires specific answers to questions such as: "What are the rules governing the relationship between the amino acid sequence and the three-dimensional structure? When the amino acid sequence is known, can the native conformation of the protein be 
predicted?" If the answer to the latter question is yes, the protein folding problem can be solved fairly easily. ${ }^{3}$

Solving the protein folding problem has a major biological significance. The currently ongoing Human Genome Project will produce a large number of amino acid sequences for proteins whose structures and functions are not known. The solution to the protein folding problem will allow the direct translation of such sequences into threedimensional structures without the need for X-ray crystallography. This would most certainly expedite the full interpretation of the data obtained from this project.

\subsubsection{Mechanism of Protein Folding}

Although most proteins fold spontaneously into their native states, the net stability of the native structure is very low. The process of folding and unfolding is usually reversible. Refolding of the protein can be achieved by treating an unfolded protein with conditions in which the folded state is stable. This refolding is a self-assembly process and it is found that the information required for the protein to fold is contained in the amino acid sequence itself.

The folding of a polypeptide is directed and not a random event. For example, a polypeptide chain containing 100 residues has $2^{100}$ possible conformations. This does not include the conformation about the side chains and thus represents the absolute minimum number of conformations. If we consider that the shortest amount of time to achieve one conformation is $10^{-13}$ seconds, the average time for this polypeptide chain to try out all possible conformations would be $10^{85}$ seconds. In contrast to this, a typical protein with 
200 to 300 residues folds in $10^{-1}$ to $10^{3}$ seconds. Thus, it is obvious that proteins do not search all possible conformations, but achieve their native folded structure by going through specific conformations that lead to the native state. The characterization of these intermediate states is paramount for understanding the mechanism and the pathway of protein folding.

\subsubsection{Models for Protein Folding}

Several models have been proposed to explain the folding mechanism of proteins. Each of these models takes a different approach and is described below.

\subsubsection{Nucleation, Rapid-Growth Model}

The nucleation, rapid-growth model proposed by Wetlaufer in 1973 suggests that in the initial stages, some of the amino acids in the random coil of the protein coagulate in a random manner to form a localized center known as the nucleation center. As shown in Figure 2, this slow step is the rate-limiting step. Folding then proceeds rapidly about the nucleation center to form the native structure without populating intermediate structures. This model does not explain the vast amount of experimental data that indicates the existence of structural intermediates formed during the folding of many different proteins and as such. it is not assumed to play a major role in the folding process. ${ }^{5}$ 


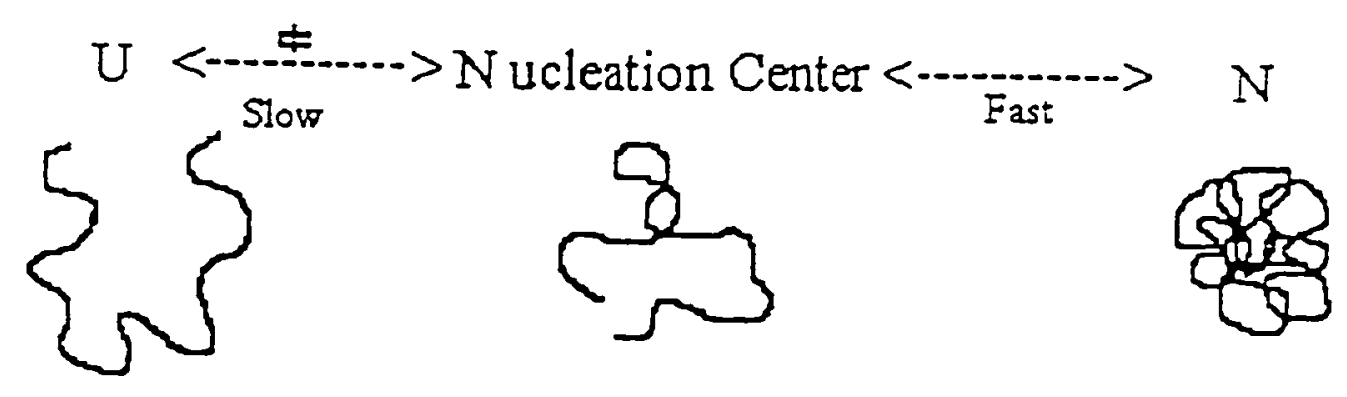

Figure 2: Nucleation rapid-growth model. 


\subsubsection{Jigsaw-puzzle Model}

Another early model for protein folding is the jigsaw-puzzle model. In this model. each unfolded structure folds to the same native structure and does so through a unique set of steps that are defined by the structure of the varticular unfolded state as shown in Figure 3. No particular intermediate structure is populated during folding and the kinetics is defined by a large collection of rates, one for each unfolded state. This model cannot explain the population of specific intermediate states that has been observed in the

folding of many proteins. ${ }^{6}$ Furthermore, the folding of many proteins has been shown to be independent of the denaturing conditions and hence, the structure of the unfolded state.

\subsubsection{General Model}

The general model for protein folding (Figure 4) assumes that a unique set of unfolded structures are in rapid equilibrium under denaturing conditions. Upon initiation of folding, these states rapidly equilibrate with the same and smaller set of intermediate partially-folded structures. These intermediate structures then equilibrate with an even smaller set of more nativelike intermediate structures. The process continues in this manner until the native state is formed.

\subsection{Dominant Forces in Protein Folding}

The complex nature of the protein folding problem leads to some interesting questions. How does the large size of the polypeptide chains enable them to fold back 


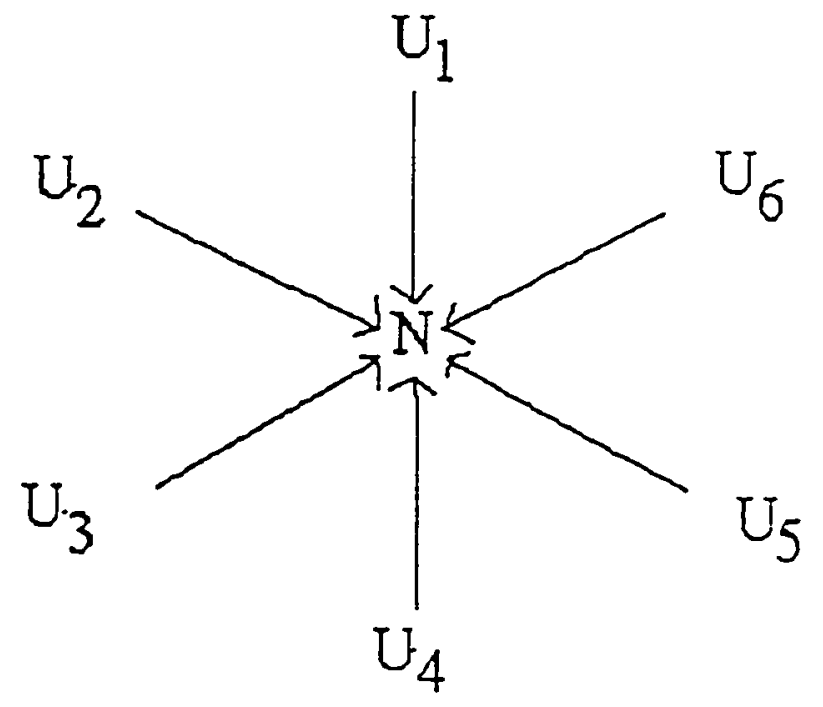

Figure 3: Jigsaw-puzzle model. 


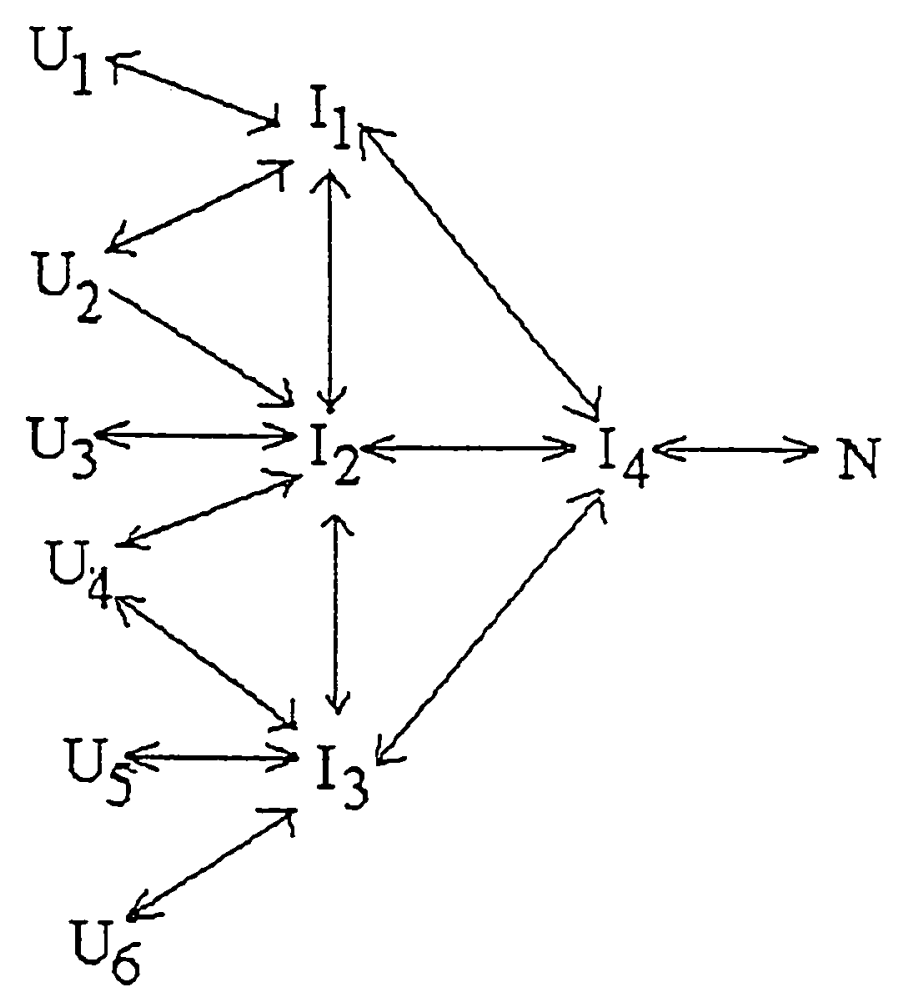

Figure 4: General model. 
onto themselves? What are the main interactions between these residues? The interactions that are either covalent or non-covalent are important and merit some discussion in depth. A recent review by Dill et al. discusses the different forces that are dominant in the protein folding process. ${ }^{8}$ The main forces involved in the folding are described in the following sections.

\subsubsection{Electrostatics}

As acids and bases were among the earliest known protein denaturants, all intramolecular forces were initially thought to be electrostatic in origin. The first quantitative model of electrostatic interaction proposed by Linderstrom-Lang in 1924 treats a native protein as the sum of charged spherical particles. Coulomb's Law states that the energy of interaction between ions $A$ and $B$ in a vacuum is defined by

$$
\Delta E=\frac{Z_{A} Z_{B} \varepsilon^{2}}{r_{A B}}
$$

where $\Delta E$ is the energy between the two atoms, $\varepsilon$ is the charge of an electron, $Z$ is the number of such charges on each ion and $r$ is the distance between them. In proteins, the electrostatic interaction forces depend upon the number of charges and their distributions that are different for native, partially-folded and denatured states. The conformational stability of the protein in any state is defined by a combination of: classical electrostatic repulsions and specific electrostatic attractions.

At the isoelectric $\mathrm{pH}(\mathrm{pI})$, proteins have no charge, as there are equal numbers of positive and negative charges. At $\mathrm{pH}$ values below and above the pI. proteins have an 
excess of either positive or negative charges respectively. The greater the difference between the $\mathrm{pH}$ and the $\mathrm{pI}$, the larger the overall charge that leads to a larger repulsive force and an accompanying reduction in the overall stability. On the other hand. neighboring charges of opposite polarity can form salt bridges that serve to stabilize the

protein structure. The combined electrostatic interactions among the repulsive and attractive charge groups in the protein contribute towards the overall conformational stability of proteins.

\subsubsection{Hydrogen Bonding}

One type of electrostatic interaction between polar amino acids is known as hydrogen bonding. In hydrogen bonding, a hydrogen atom is shared between a proton donor (acid) and a proton acceptor (base). The energy associated with these interactions depends upon the nature of the donors and acceptors, and the geometry of the molecule. Figure 5 shows typical hydrogen bonds found in proteins. Most of the hydrogen bonding in the protein occurs between the carbonyl oxygen and the amide hydrogen of the peptide backbone. These hydrogen bonds serve to stabilize the secondary structure of the protons. In addition, dipolar amino acid side chains can form hydrogen bonds with each other or with surrounding water molecules. Although an individual hydrogen bond contributes little to the stability of a protein, the sheer number of hydrogen bonds found in a protein cumulatively leads to a significant contribution to its overall stability.

Typically, all polar groups located in the interior of a protein are paired in hydrogen bonds. Most of these polar structures are on the polypeptide backbone and 


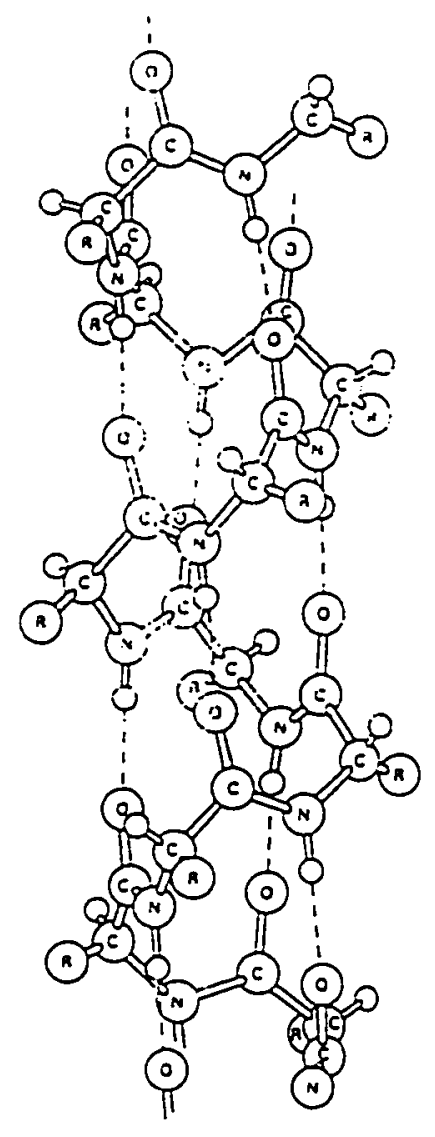

Figure 5: Typical hydrogen bonds in proteins. (reproduced with permission from Lehninger, A. L.; Nelson, D. L.; Cox, M. M. Principles of Biochemistry; Worth: New York. 1993; p 167). 
usually contribute to the secondary structure of the protein. Water molecules are generally excluded from the interior of the protein. Most of the ionized groups in watersoluble proteins are located at the surface and exposed to the allowing them to form hydrogen bonds with it. Since the polar groups are situated in greater proximity to each other than the water molecules, the hydrogen bonds between the polar groups are stronger than those between the water molecules and the polar groups.

\subsubsection{Hydrophobic Interaction}

Several aspects should be considered when defining hydrophobic interactions. Hydrophobic interactions are best defined in terms of the free energy of solvation. To facilitate solvation of apolar amino acids, water molecules form a highly structured cavity about these residues. Although this is an enthalphically favorable process, the ordering of the water molecules gives rise to a highly unfavorable solvent entropy. In order to minimize the entropy of the solvent, the non-polar amino acids come together to form a "hydrophobic core" to avoid water contact which in turn stabilizes the protein structure. Thus, polar amino acids in the protein are typically exposed to the solvent while nonpolar amino acids are situated in the interior of the protein.

\subsection{Basic Techniques for Monitoring Protein Folding}

\subsubsection{Absorbance}

Absorbance spectroscopy is widely used to examine protein stability and to monitor the folding process. Typically, the near-UV absorbance of the aromatic side 
chains (Phe, Tyr, and Trp) is monitored. The absorbance spectra for these side chains are dependent on their local environment and differ markedly when they are buried within the hydrophobic core of a protein as opposed to when they are exposed to the hydrophilic environment on the surface of a protein. Thus, disruption of the tertiary structure that accompanies denaturation necessarily leads to a change in the protein's near- $\mathrm{UV}$ spectrum, as the local solvent environment about the aromatic side chains changes. Such spectroscopic changes provide a convenient method to monitor the extent of this disruption.

Solvent exposure of aromatic side chains during the denaturation process typically causes a red-shift in the protein's absorbance spectra. In the present study, the absorbance at $286 \mathrm{~nm}$ is monitored. Since this wavelength is located on the long wavelength side of the native protein's absorption band, denaturation leads to a decrease in the absorbance at this wavelength.

\subsubsection{Fluorescence}

Fluorescence is commonly employed to study the structure and dynamics of proteins. The aromatic amino acids (Trp, Tyr) act as fluorescence probes in the proteins. In its native structure, the protein shows minimum fluorescence due to the fluorescence quenching caused by tight packing of side chains. As the protein unfolds, the quenching decreases resulting in increased fluorescence. 


\subsubsection{Circular Dichroism (CD)}

When circularly polarized light is passed through a solution of an optically active substance, either left-handed or right-handed circularly polarized light is preferentially absorbed. The difference in absurption is known as circular dichroism. CD is observed only in the wavelength regions where the substance absorbs light and can be either positive or negative. In proteins, the major absorbing species is the peptide bond. The organized secondary structures of the protein are optically active and give distinctive CD spectra. Thus, the CD spectra of proteins provide a very sensitive measure of the integrity of secondary structures. The amplitude of the CD signal at $222 \mathrm{~nm}$ has been used to measure the $\alpha$-helical content in the protein since the signal from this structure is large and the contributions from the other structures are minimum at this wavelength.

\subsubsection{Differential Scanning Calorimetery}

Differential scanning calorimetery (DSC) provides a direct measurement of the energetics associated with folding and unfolding transitions. Brandts et al. performed calorimetric experiments on a variety of proteins and showed that DSC can also provide thermodynamic information for folding intermediates populated during the transition. ${ }^{10}$ Calorimetery, however, does not provide direct information regarding the nature and identity of the folding intermediates and as such it must be supplemented with some other techniques. 


\subsubsection{Electrophoresis}

Electrophoresis has been used to study protein folding and unfolding. The electrophoretic mobility of a molecule depends upon the charge to size ratio. As the protein unfolds, the charge and the size of the protein changes causing a change in its electrophoretic mobility. Thus, by calculating the electrophoretic mobility of a protein as it unfolds, one can determine the change in the charge as well as the size of the protein.

In the past, electrophoresis involved the use of a slab gel where the migration of the folded and unfolded states was observed. Although it is one of the most widely used separation techniques, slab gel electrophoresis generally has the disadvantages of long analysis times, low efficiencies, and difficulties in detection and automation. High performance capillary electrophoresis (HPCE) has a number of advantages over this technique including higher efficiency, usage of smaller sample volume, simplicity. selectivity, and wide application range."

\subsection{Equilibrium Method for Unfolding and Refolding of Proteins}

It has been observed that many small proteins can unfold reversibly in a cooperative manner without any indication of a partially folded state. ${ }^{12}$ In such cases, the folding can be described by a two-state transition involving only the native species.$V$ and the fully unfolded species $U$. The equilibrium transition can be written as follows:

$$
N \Leftarrow \Rightarrow U
$$

A native protein can be unfolded by adding chemical denaturants or by altering factors like temperature, $\mathrm{pH}$ and solvent. the alteration serving to shift the equilibrium in favor 
of the unfolded state. At any point in the transition, the relative population of native and unfolded protein is related to the equilibrium constant $K_{e q}$ :

$$
K_{e q}=\frac{[U]}{[N]}
$$

Under mild conditions of the denaturant, the native state is the dominating species, but the unfolded state is favored increasingly as the denaturant concentration is raised. Figure 6 shows a typical denaturation curve for proteins. The point at which both the folded and unfolded states coexist with an equilibrium constant of unity is known as the transition midpoint.

For the non-cooperative transition, the two-state approach is not valid, as one or more partially unfolded intermediate states are present besides the native and unfolded states. In a simple case, where only one intermediate state $I$ can be populated, the equilibrium expression becomes:

$$
N \Leftarrow I \Leftarrow \Rightarrow
$$

The overall equilibrium constant $K_{\text {eq overall }}$ is given by:

$$
K_{\text {eq uverall }}=K_{1} \times K_{2}
$$

where

$$
K_{1}=\frac{[I]}{[N]}
$$

and 


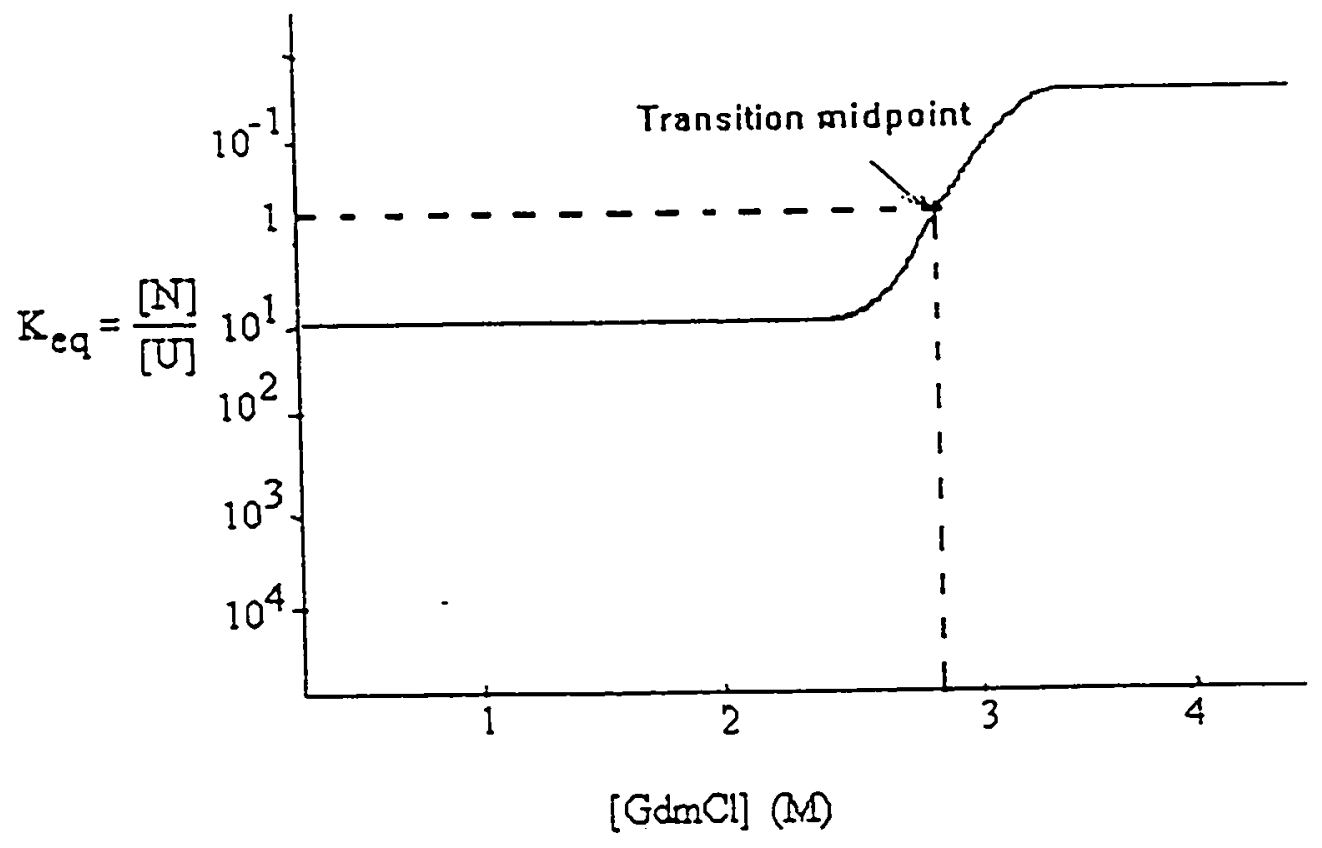

Figure 6: Typical denaturation curve. 


$$
K_{2}=\frac{[U]}{[I]}
$$

\subsubsection{Protein-Stability-and-pH-Effect}

Many proteins unfold at $\mathrm{pH}$ values less than about $\mathrm{pH} 5$ or greater than $\mathrm{pH} 10$. Unfolding at such extremes of $\mathrm{pH}$ usually occurs because the folded protein has groups buried in a nonionized form that can ionize by unfolding. Along with the electrostatic repulsion, salt bridges between ionizing groups that contribute to the stability of the protein are broken down, as the interacting groups are no longer ionized.

The $\mathrm{pH}$ dependence of unfolding can be observed in urea or guanidinium chloride ( $\mathrm{GdnHCl})$-mediated denaturation. The investigation carried out by Pace et al. indicates that the $\mathrm{pH}$-related stability of RNase $\mathrm{A}$ and $\mathrm{RNase} \mathrm{T}_{1}$ depends mainly on the electrostatic interaction involving the charged groups and the differences between the pK values of the ionizable groups in the folded and unfolded conformations. ${ }^{13}$ Thus, a change in the $\mathrm{pH}$ value can cause a change in $\Delta \mathrm{G}$ which affects the stability of the protein as shown in Figure 7. Further, they found that proteins are generally most stable at their pI.

One of the simplest and most commonly used methods for unfolding a protein is to increase the temperature. As the temperature increases, the solubiiity of hydrophobic groups increases and the hydrogen bonds weaken. At a very high temperature, the protein completely loses its compact structure and forms a random coil. 

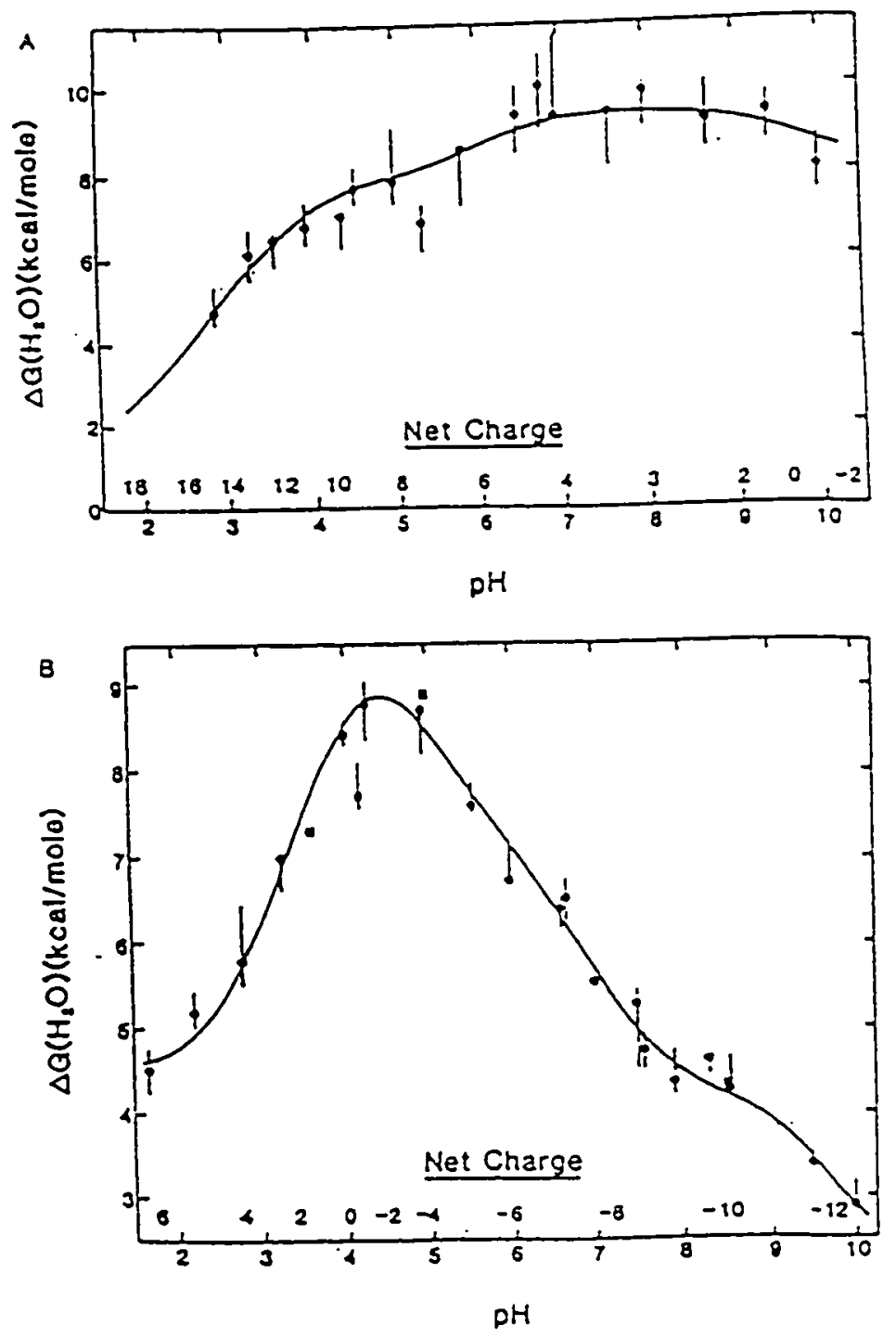

Figure 7: $\Delta \mathrm{G}\left(\mathrm{H}_{2} \mathrm{O}\right)$ as a fuction of the unfolding of RNase $A(A)$ or RNase $T_{1}(B)$ (reproduced with permission from Pace, C. N.; Laurents, D. V.; Thomson, J. A. Biochemistry 1990. 29, 2564, ( ) by the American Chemical Society). 
Figure 8 shows the thermal denaturation of RNase A over a wide range of $\mathrm{pH}^{14}$ Here, UV absorbance was used to observe the unfolding of RNase A. As expected. the transition midpoint for each denaturation curve increases with an increase in $\mathrm{pH}$. As shown in Figure 9, Ginsberg et al. observed the thermal denaturation of RNase $A$ by measuring the intrinsic viscosity of the protein and found that changes in the UV absorbance were concurrent with changes in viscosity. ${ }^{15}$ Since the intrinsic viscosity of a protein is a measure of its effective hydrodynamic volume, it changes with the hydrodynamic volume as the protein's conformational states change during unfolding.

\subsubsection{Use of Chemical Denaturants}

A large number of reagents affect the stability of the protein. Those that decrease protein stability are known as denaturants. Chemical denaturants such as urea, guanidinium chloride and alchohols are commonly used to study the folding process. These denaturants compete for hydrogen bonding and increase the hydrophobicity of the solvent thereby breaking the hydrogen bonds along the peptide backbone and causing denaturation of the protein. The hydrophobic effect also plays a major role in the unfolding process. Urea and $\mathrm{GdnHCl}$ increase the solubilities of the polar and non-polar amino acids in proportion to their accessible surface areas, thus causing a decrease in the magnitude of the hydrophobic interaction that leads to unfolding of the protein. Ghuman et al. have examined the denaturation of RNase $A$ with a number of alkylureas ard urea. ${ }^{16}$ The data as shown in Figure 10 suggests that as the number of hydrogen bond donors in 


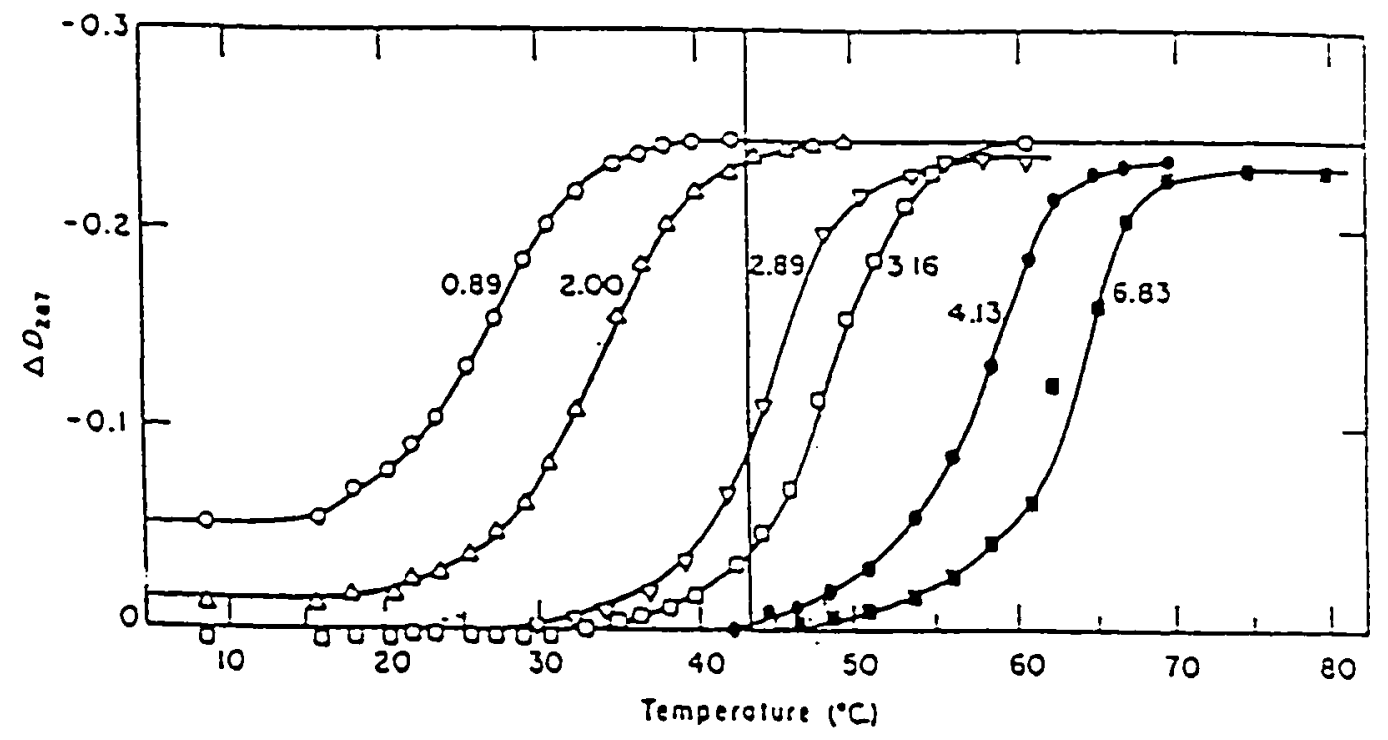

Figure 8: The thermal denaturation of ribonuclease at several $\mathrm{pH}$ values at 0.16 ionic strength, followed by difference absorption measurement (reproduced with permission from Herman, J.; Scheraga, H. A. J.Am. Chem. Soc. 83, 3283, 1961, ( by the American Chemical Society). 


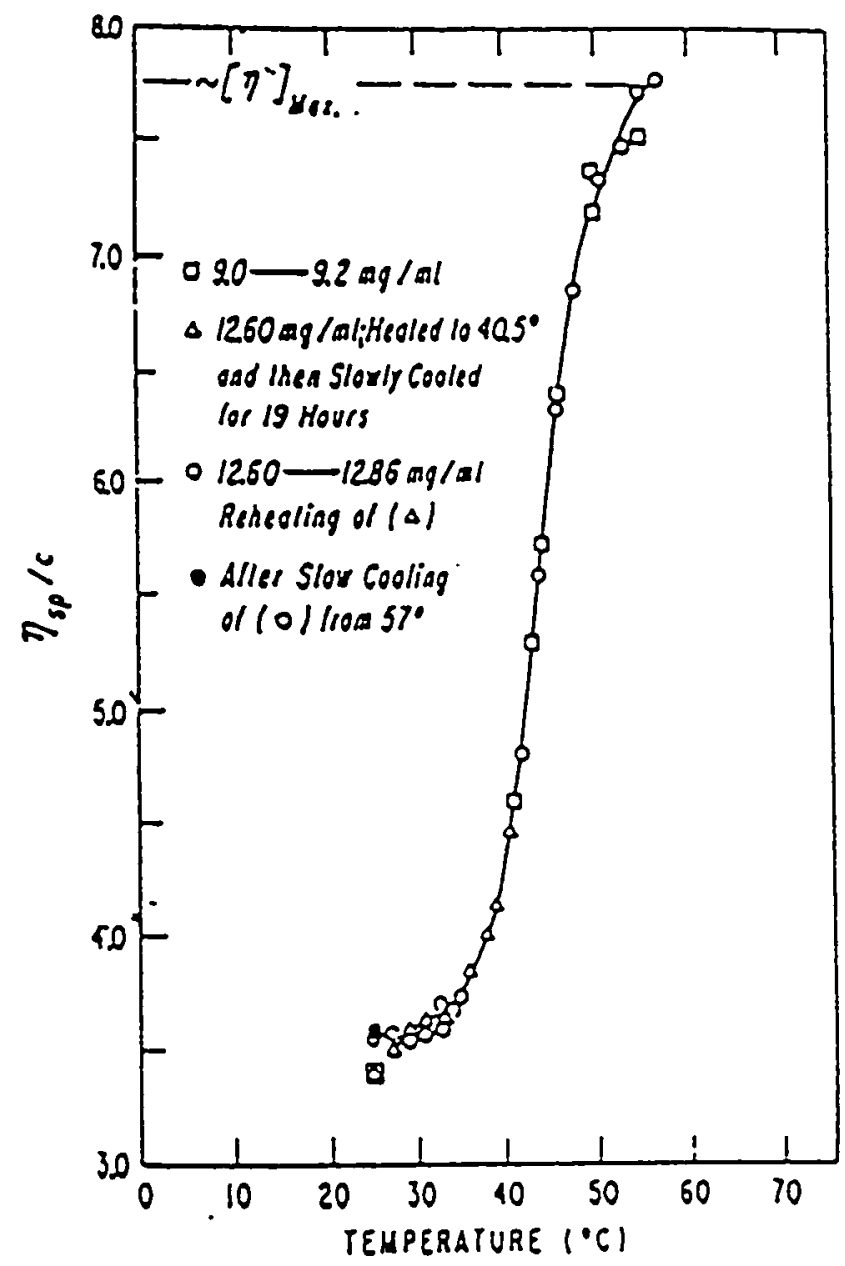

Figure 9: The reduced viscosity of ribonuclease in a $\mathrm{SO}_{4}{ }^{2-}$-HSO4. buffer at $\mathrm{pH} 2.1$ and 0.019 ionic strengths as a function of temperature (reproduced with permission from Ginsberg, A.; Carroll, W. R. Biochemistry 1965, 4, 2159. () by the American Chemical Society). 


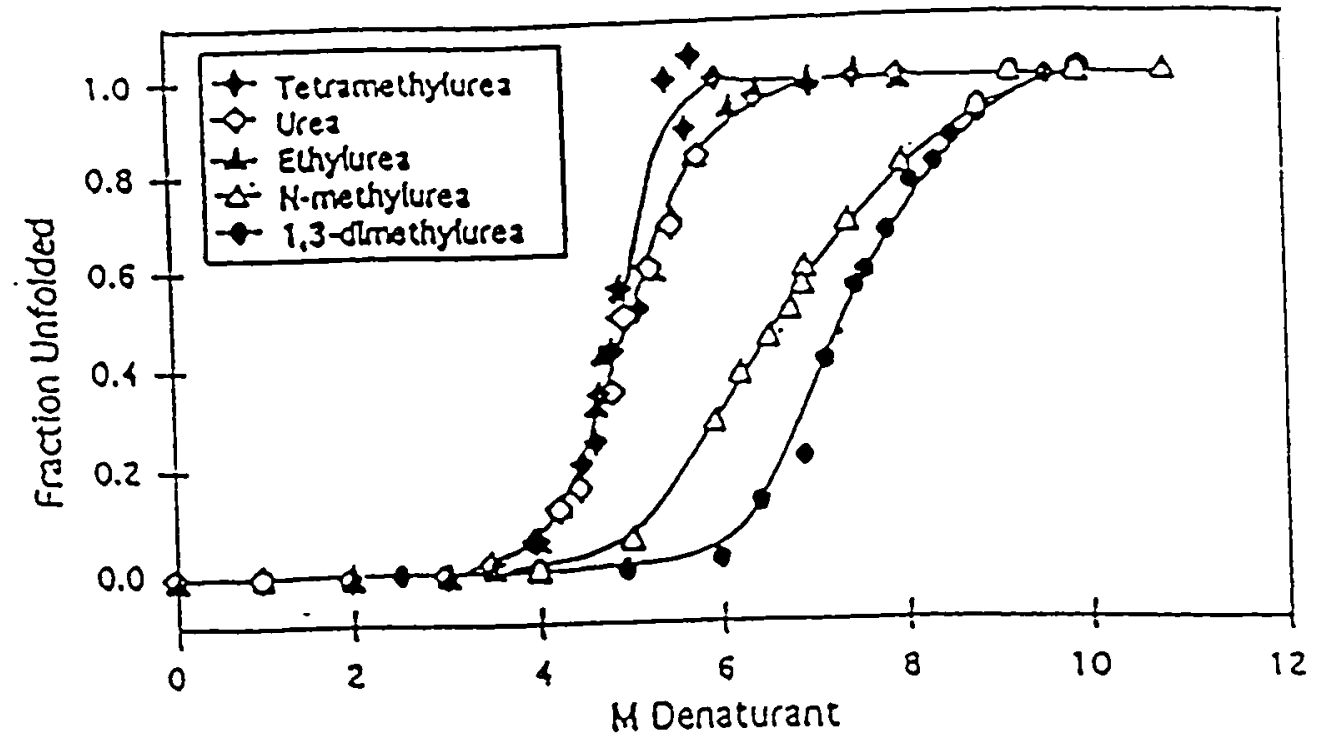

Figure 10: Alkylurea studies. Denaturation profile of $\mathrm{RNase} A$ using a variety of alkylureas at $\mathrm{pH}^{*} 4.00$ and $17{ }^{\circ} \mathrm{C}$ as monitored by the intrinsic fluorescence $(280 / 350$ $\mathrm{nm})$. Raw data was standardized by conversion to fraction of unfolded molecules.

(Reproduced with permission from Ghuman, R.; Henriquze, V.; Biringer, R. G.; San Jose State University, unpublished results). 
the denaturant decreases, the concentration of the alkylurea necessary to denature the protein increases. This strongly suggests the idea that hydrogen bonding is a significant factor in stabilizing protein structures. As the hydrophobic nature of the denaturant changes, the concentration required to denature the protein changes. Thus, in addition to the hydrogen bonding, hydrophobic interactions also play an important role in protein stability.

\subsection{High Performance Capillary Electrophoresis (HPCE)}

As mentioned in the previous section, HPCE is becoming increasingly popular as a method for studying protein folding. It is important to understand the instrumentation and theory behind the technique before it can be applied effectively. Several factors bear consideration when working with the instrument and in developing a method.

\subsubsection{Instrumentation}

"Electrophoresis has been defined as the differential movement of any charged species or ions by attraction or repulsion in an electric field". In the early 1980 s, Jorgenson et al. used a fused silica capillary to carry out electrophoretic separation. ${ }^{18}$ In his paper, Jorgenson explains the theory behind the technique, describes the relationship between the variable parameters and the separation quality, and demonstrates the potential of HPCE as an analytical technique. As shown in Figure 11, a key feature of this instrument is its simplicity. Generally, electrophoresis is performed in a narrow-bore 


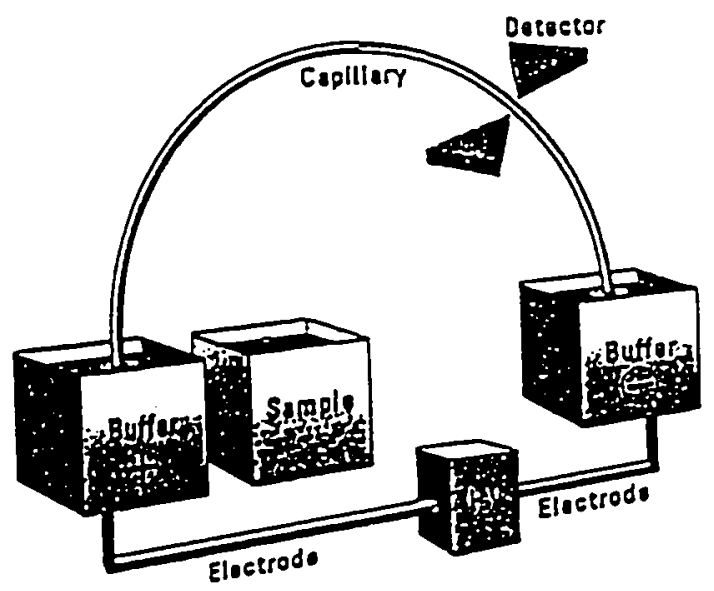

Figure 11: HPCE Instrumentation (reproduced with the permission from Heiger, D. N. High Performance Capillary Electrophoresis; Hewlett-Packard: France, 1992; p 6). 
silica capillary $25 \mathrm{~mm}$ to $100 \mathrm{~mm}$ in diameter with its ends placed in the buffer reservoirs. The content of the reservoir is identical to that within the capillary. Two electrodes are placed in the reservoirs to make an electrical contact between the high voltage power supply and the capillary. The sample is loaded into the capillary by (usually at the anode) with a sample ieservoir and applying either an electric field or external pressure of about 5 mbar to 50 mbar. After sample injection, the end of the capillary is replaced with the buffer reservoir and the electric field is applied to perform the separation. Jorgenson used a UV detector placed at the opposite end of the injection end as an optical detector.

\subsubsection{Basic Principle (Theory)}

Separation by electrophoresis is based on the differences in solute velocity in an electric field. The two important parameters responsible for the mobility of any solute or ion are the electrophoretic mobility and electroosmotic flow (EOF).

\subsubsection{Electrophoretic Mobility}

Electrophoretic separation is based on differences in the solute velocity in the presence of an electric field. The velocity of an ion is given by the equation

$$
v=\mu_{e} E
$$

where $v$ is the ion velocity, $\mu_{e}$ is the electrophoretic mobility and $E$ the applied electric field is a function of the applied voltage and capillary length.

Therefore, 


$$
\mu_{e}=\frac{v}{E}
$$

The electrophoretic mobility is also a balance between its electric force and its frictional force through the medium. The electric force $\left(F_{E}\right)$ can be given by

$$
F_{E}=q E
$$

$q$ where is the ionic charge. For any spherical ion, the frictional force $\left(F_{F}\right)$ is given by

$$
F_{F}=-6 \pi \eta r v
$$

where $\eta$ is the solution viscosity and $r$ is the ionic radius.

During electrophoresis, both the forces are equal but opposite and therefore,

$$
q E=6 \pi \eta r v
$$

Therefore, combining equations 9 and 12 ,

$$
\mu_{e}=\frac{q}{6 \pi \eta r}
$$

From equation 13 it is clear that small, highly charged ions have high mobilities whereas large and minimally charged ions have low mobilities as shown in Figure 12.

The above statement is true for spherical ions or proteins. For non-spherical proteins, the electrophoretic mobility is proportional to the ratio of its charge to its hydrodynamic volume. Since the hydrodynamic radius and the effective net charge of the protein are functions of the three-dimensional structure of the protein, one can study the unfolding of the protein by measuring its electrophoretic mobility. 


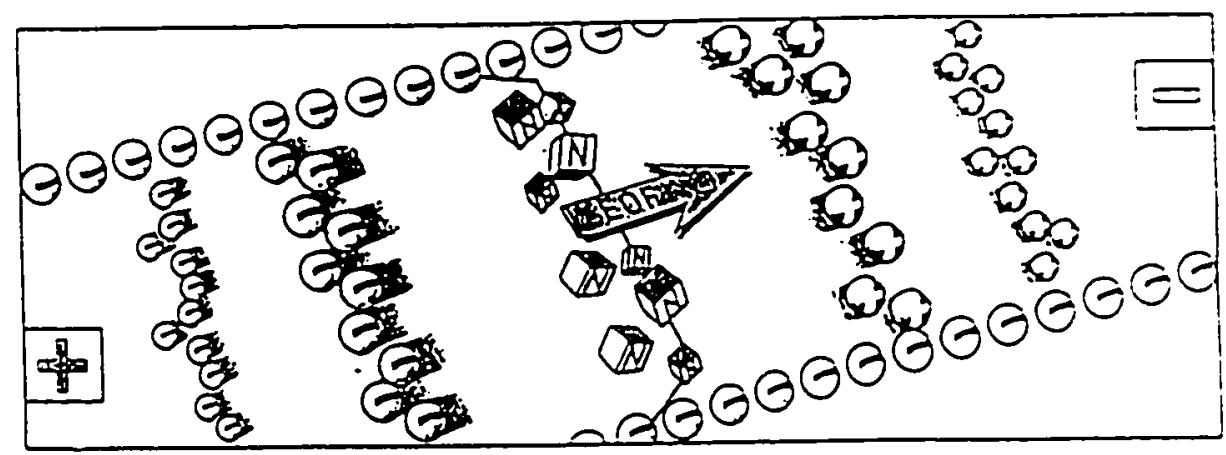

Figure 12: Differential solute migration superimposed on electroosmotic flow in CZE (reproduced with the permission from Heiger, D. N. High Performance Capillary Electrophoresis; Hewlett-Packard: France, 1992; p 19). 


\subsubsection{Electroosmotic Flow (EOF)}

EOF is the bulk flow of the liquid in a capillary resulting from the effect of the applied field and the resistance of the inner wall of the capillary. Under aqueous conditions, most solid surfaces possess an excess of negative charges. This can result from ionization of the surface and/or from adsorption of ionic species at the surface. Both processes occur in the case of fused silica although the EOF is strongly controlled by many silanol groups $(\mathrm{SiOH})$ that can exist in anionic form $\left(\mathrm{SiO}^{-}\right)$. Counter ions (mainly cations) can build up near the surface to maintain the charge balance thus forming a double layer as shown in Figure 13. This creates a potential difference called the zeta potential $(\zeta)$ very near the wall of the capillary. When voltage is applied across the capillary, the cations forming the diffuse double layer are attracted towards the cathode. Since these ions are solvated, their moment drags the bulk solution in the capillary towards the cathode (Figure 14). The magnitude of the EOF can be expressed in terms of the solvent velocity as

$$
\mu_{E O F}=\frac{\varepsilon \zeta}{\eta}
$$

where $\mu_{E O F}$ is the EOF mobility, $\varepsilon$ is the dielectric constant, $\zeta$ is the zeta potential and $\eta$ is the viscosity of the medium. The EOF causes movement of nearly all species, regardless of their charge, in the same direction. As seen earlier in Figure 12, the cations migrate fastest since the EOF and the electrophoretic attraction towards the cathode are in the same direction, the neutrals are all carried at the velocity of the EOF and the anions 


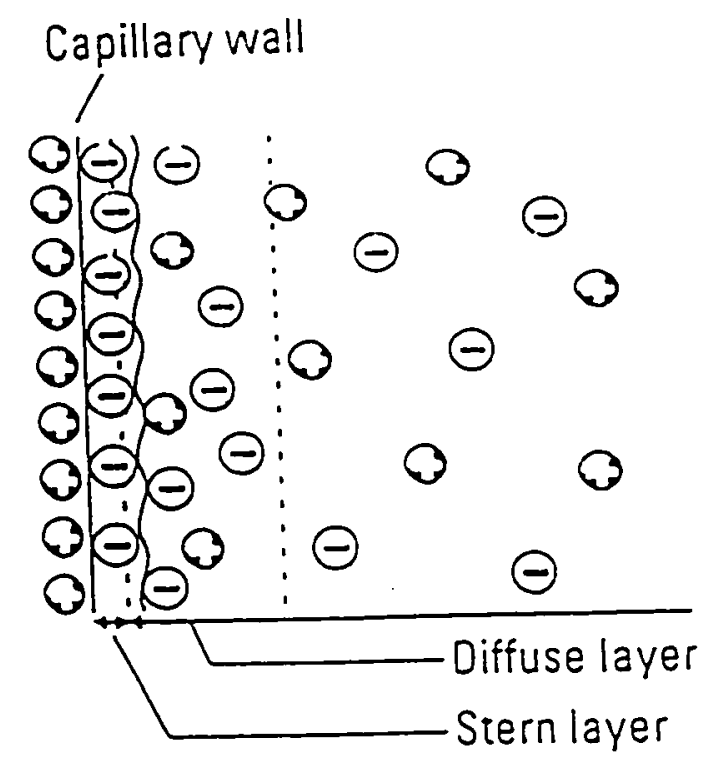

Figure 13: Representation of the double layer at the capillary wall (reproduced with the permission from Heiger, D. N. High Performance Capillary Electrophoresis; HewlettPackard: France, 1992; p 15). 

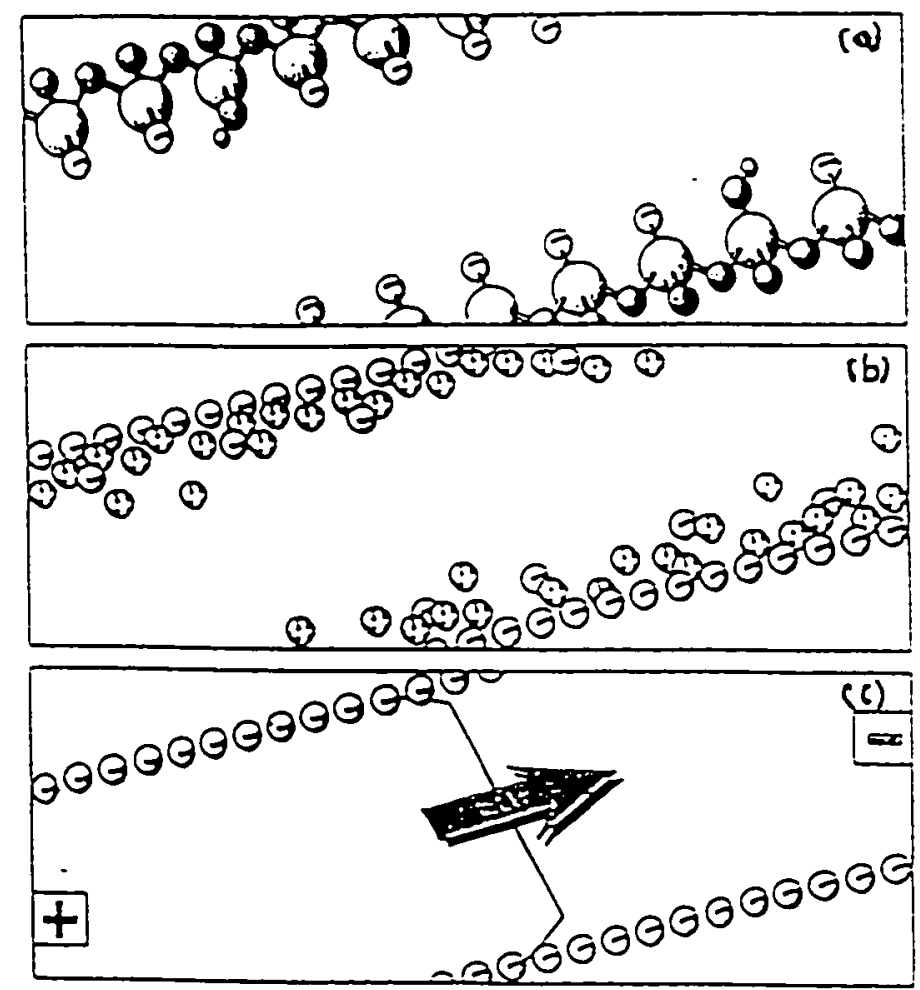

Figure 14: Development of the electroosmotic flow:

(a) Negatively charged fused silica surface (Si-O)

(b) Hydrated cations accumulating near the surface

(c) Bulk flow towards cathode upon application of electric field (reproduced with the permission from Heiger, D. N. High Performance Capillary Electrophoresis; Hewlett-Packard: France, 1992; p 15). 
migrate slowest since they are carried by the EOF towards the cathode against their attraction to the anode.

The zeta potential is essentially determined by the surface charge on the capillary wall. Since this charge is $\mathrm{pH}$ dependent, the magnitude of the EOF varies with $\mathrm{pH}$. At high $\mathrm{pH}$. where the silanol groups are deprotonated, the EOF is greater than at low $\mathrm{pH}$ where the silanol groups are protonated. Thus, EOF depends strongly on $\mathrm{pH}$ and increases with the $\mathrm{pH}^{\text {"I }}$

\subsubsection{Capillary Zone Electrophoresis (CZE)}

CZE is the most commonly used mode in High Performance Capillary Electrophoresis (HPCE). It is the simplest form of HPCE where the capillary is filled with the buffer solution only and separation occurs in discrete zones along the capillary as explained in the previous section. Solutes with different mobilities migrate differently and neutral solutes coelute with the EOF.

CZE has been widely applied to separate proteins and peptides. While there are numerous examples of the separation of small molecules such as amino acids and peptides by CZE, the application of CZE to proteins has been limited due to the adsorption of the protein on the capillary wall. McCormick et al. performed CZE using a capillary with a deactivated silica surface and were able to separate a broad range of

proteins which differed only by a few amino acids in their sequence. ${ }^{17}$ The capillary surface was deactivated by treating the bare fused silica capillary with the phosphate buffer. This results in the formation of a phospho-silicate complex near the inner 
capillary wall and reduces the protein interaction towards the wall leading to an effective separation.

\subsubsection{Factors affecting the efficiency}

This section focuses on the main concerns regarding the $C E$ instrument that must be addressed before performing the separation. Some solutions are also discussed briefly.

\subsubsection{Joule Heating Effect and Temperature Gradient}

The measurement and control of the temperature in HPCE are essential for a meaningful and reproducible result. Controlling the buffer temperature is critical since it affects most of the important parameters in the separation.

In any electrophoretic experiment, heat is generated due to the application of voltage to the system which results in an electrical current. This heat is called the Joule heat. The amount of heat generated can be determined from the voltage and current relationship as stated by Ohm's law

$$
P=I V
$$

where $P$ is the applied power in milliwatts, $I$ is the current generated in microamps and $V^{\prime}$ is the voltage in kilovolts. Thus, the heat dissipated is directly proportional to the applied voltage.

As shown in Figure 15, an increase in the voltage causes a corresponding increase in 


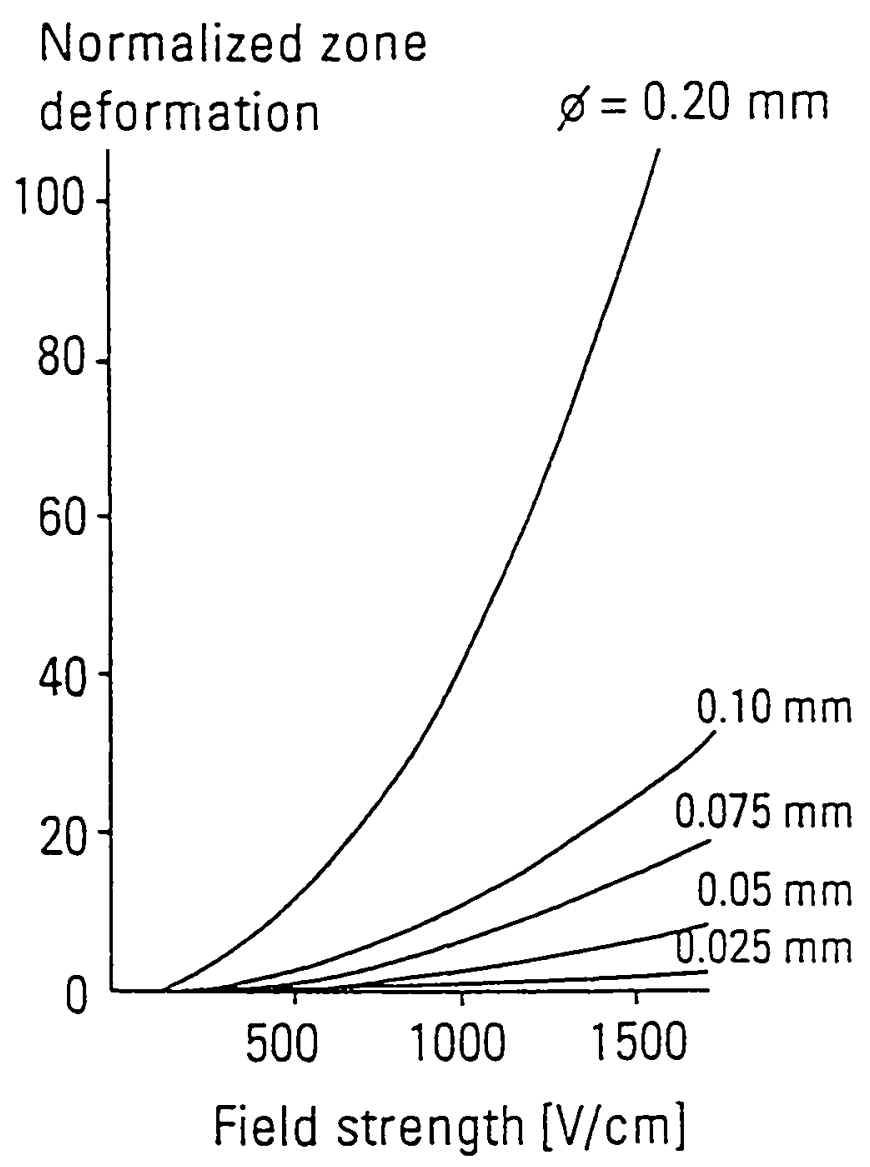

Figure 15: Effect of Joule heating and temperature gradients on solute zone deformation ( $\phi=$ capillary id) (reproduced with the permission from Heiger, D. N. High Performance Capillary Electrophoresis; Hewlett-Packard: France, 1992; p 28). 
the current and consequently the total power dissipated in the system. Various problems can result when this power exceeds a few watts. McCormick et al. showed that the Joule heating in the column caused by rapid application of the voltage can result in an irreproducible volume of the sample injection, boiling of the buffer, and an irreproducible migration time of the sample during electrophoresis. ${ }^{17}$

Several factors must be taken into consideration in order to minimize the Joule heat. Firstly, since the buffer composition and concentration influence the buffer conductivity, care should be taken to keep the buffer at a minimum ionic strength. Secondly, since the applied voltage has a direct effect on the Joule heat, it should be kept as low as possible although this sacrifices efficiency and fast analysis times. Another factor that comes into play is the column length. The applied power is inversely proportional to the column length and as such the Joule heat can be reduced by increasing the length of the column. Finally, the inner diameter of the column has a great effect on the heat generated since the cross-sectional area changes with the square of the radius. Therefore, a dramatic decrease in the current is observed with even a slight decrease in the inner diameter of the capillary.

It is important to note that the largest amount of heat is generated at the crosssectional center of the capillary bore. As shown in Figure 16, for the Joule heat to be dissipated, the temperature gradient from the center of the bore to the outer capillary surface must be proportional to the generated heat. This temperature gradient can cause viscosity differences in the running buffer and zone deformation resulting in band broadening. Thus, high temperatures can adversely affect the efficiency of the system. 


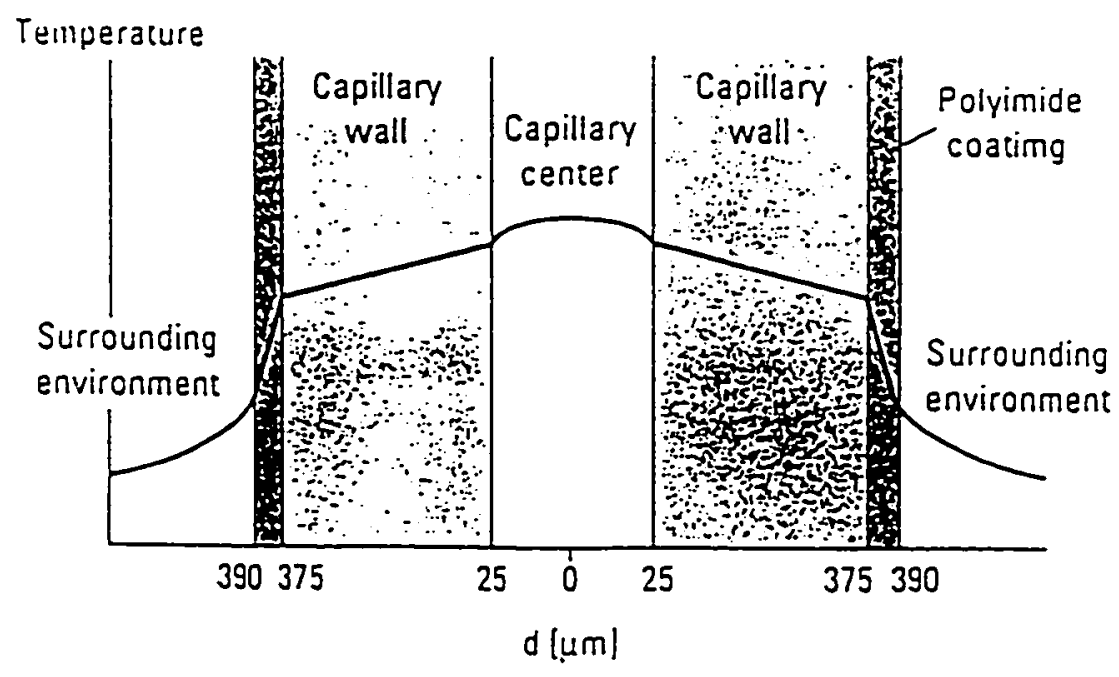

Figure 16: Temperature gradients from capillary center to the surrounding (reproduced with the permission from Heiger, D. N. High Performance Capillary Electrophoresis; Hewlett-Packard: France, 1992; p 29). 
The heat generation and the temperature gradient can be minimized by using an effective cooling system. Various cooling systems such as liquid thermostating. which uses a cool liquid passed over the outer capillary surface or air thermostating which uses cool air instead, are employed effectively for dissipating heat and maintaining a constant temperature in the system as shown in Figure 17.

\subsubsection{Electrodispersion}

In an electophoresis experiment, differences in sample zone and running buffer conductivities can result in skewed peak shapes, and can affect the peak resolution. As seen in the Figure 18, when the solute zone has a higher mobility than the running buffer. the leading edge of the solute zone will be diffused causing a sharp trailing edge and vice versa. This is known as electrodispersion. These peak shape distortions are caused by differences in conductivities and hence field, in each zone. Peak shape distortions are detrimental only if resolution is lost. Electrodispersion can be eliminated by matching the buffer and sample conductivites. Another way to minimize electrodispersion is to keep the concentration of the background electrolyte at least two orders of magnitude higher than the concentration of the sample. In this case, the peak distortions are very negligible and can be ignored. ${ }^{19}$

\section{6. +.3 pH Hysteresis Effect}

In an electrophoretic experiment, one of the most important factors leading to good reproducibility is capillary conditioning. To obtain a reproducible result one has to 


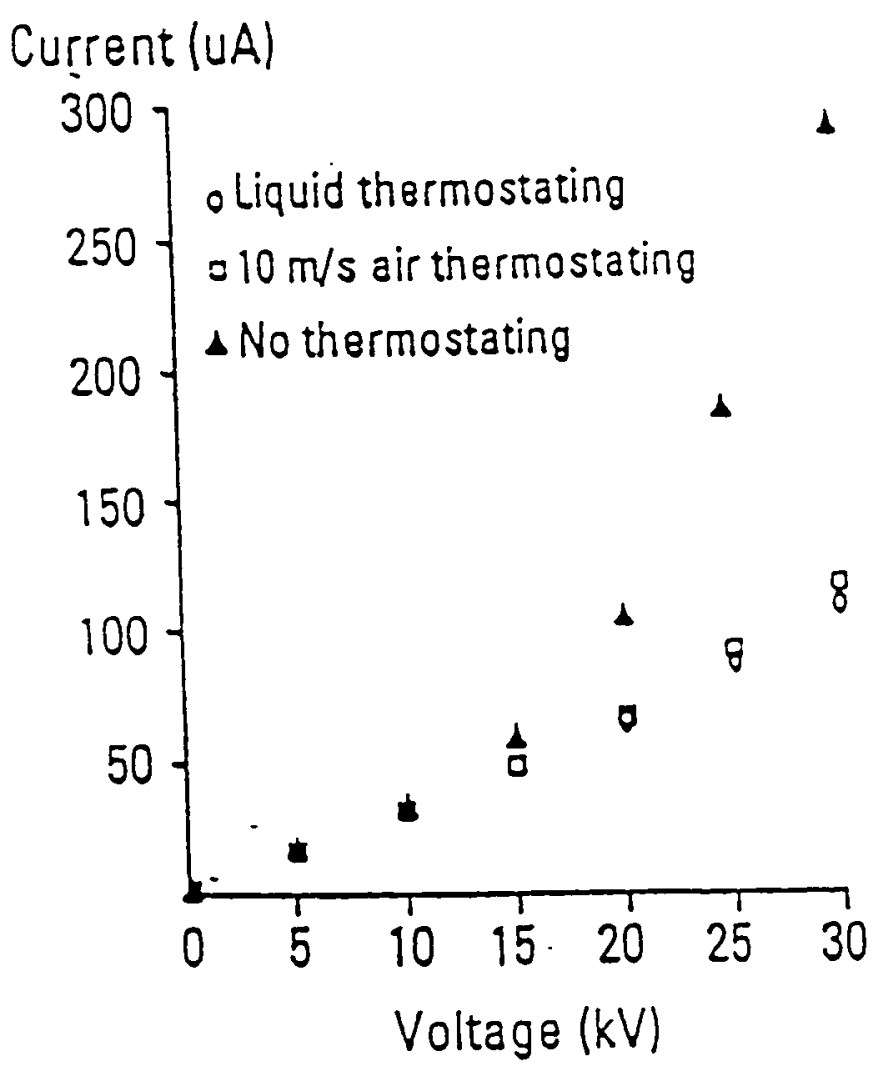

Figure 17: Methods to control Joule heating (reproduced with the permission from Heiger, D. N. High Performance Capillary Electrophoresis; Hewlett-Packard: France, 1992; p 30). 


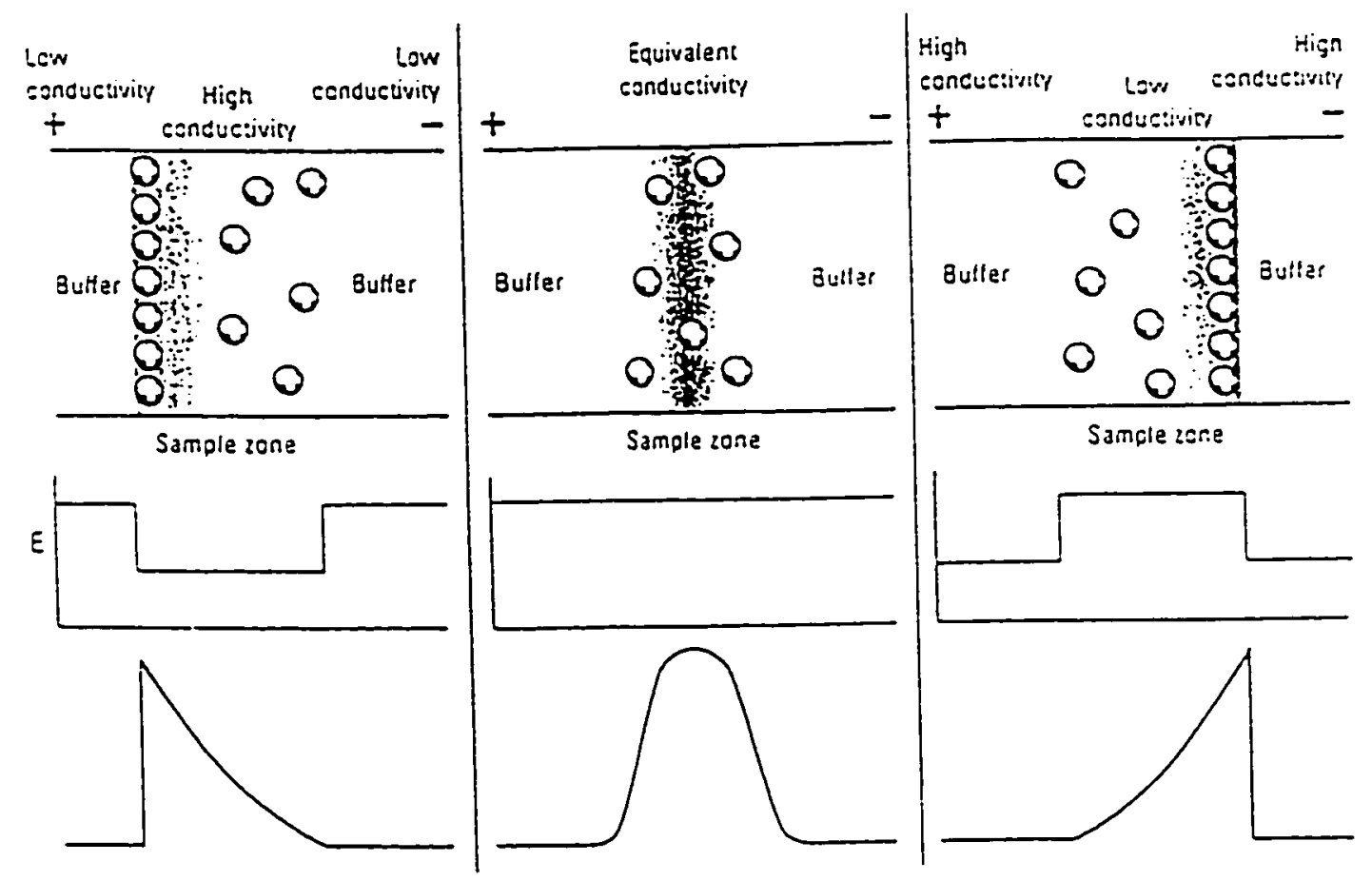

Figure 18: Electrodispersion due to mismatched sample and buffer conductivities (reproduced with the permission from Heiger, D. N. High Performance Capillary Electrophoresis; Hewlett-Packard: France, 1992; p 36). 
maintain a reproducible capillary surface. Generally, washing the capillary with the running buffer between runs yields reproducible results. With a fused silica capillary. however, the sample can be adsorbed on the inner surface of the capillary which can change the EOF, thereby affecting the reproducibility.

Treating a capillary with base helps to remove adsorbates and refresh the capillary surface by deprotonation of the silanol groups. Care should be taken with the base conditioning, especially when employing a low pH buffer. Lambert et al. observed that a hysteresis of the wall charge can cause non-reproducible EOF and longer equilibrium times. $^{20}$ Further, Lukacs et al. showed that the EOF in the fused silica capillary has a sigmoidal relationship with the $\mathrm{pH}$, as seen in Figure 19. Thus, an acid conditioning is recommended to minimize the hysteresis effect when the $\mathrm{pH}$ of the running buffer is low. The acid conditioning can result in rapid equilibration of the column with the buffer, reduce hysteresis effects, and minimize protein adsorption on the inner surface of the capillary to yield reproducible results.

\subsection{Applications of CZE to Protein Folding}

Clearly, many experimental and instrumental aspects have to be considered before using CZE to examine protein folding. This section examines the potential use of CZE in protein folding studies and is divided into two subsections. The first subsection introduces the general phenomenon of how the change in the protein structure as a function of temperature changes the electropherogram. It deals with the direct application 


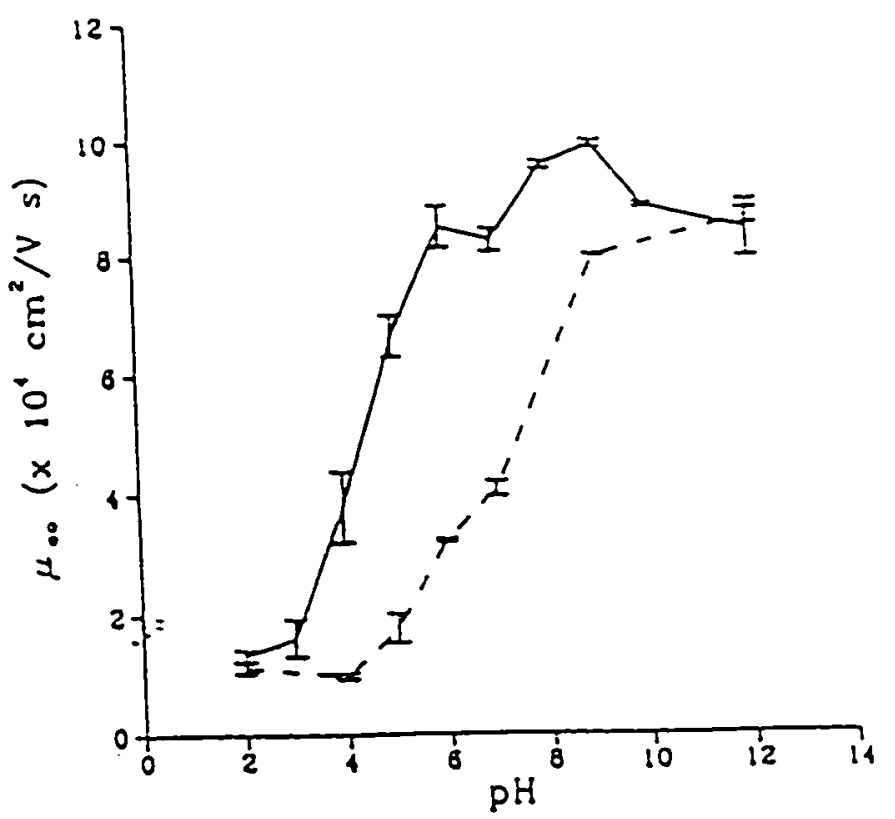

Figure 19: Effect of the electrophoretic mobility in silica capillary (ionic strength 0.01). The solid line represents alkaline to acidic conditions while dashed line represents acidic to basic conditions (reproduced with permission from Lambert, W. J.; Middleton, D. L. Anal. Chem. 1990, 63, 1346. (C) by the American Chemical Society). 
of CZE to temperature dependent protein folding studies. The next subsection explains the potential use of CZE in urea mediated denaturation studies.

\subsubsection{Temperature Study}

\subsubsection{Temperature Effect on the Electrophoretic Behavior}

The influence of column temperature on the electrophoretic behavior of myoglobin and $\alpha$-lactalbumin in HPCE was studied by Rush et al. ${ }^{21}$ Myoglobin was subjected to electrophoresis using a constant electric field and electropherograms were generated for 6 to 8 different temperatures as shown in Figure 20. At low temperatures. only one peak was observed, but as the temperature was increased from $20{ }^{\circ} \mathrm{C}$ to $40{ }^{\circ} \mathrm{C}$, a second peak along with the first peak was observed. Furthermore, at $50{ }^{\circ} \mathrm{C}$, the first peak disappeared and the second peak became sharper. Since there were no changes in the absorbance at wavelengths of 214 and $410 \mathrm{~nm}$, they concluded that there was no change in the conformation of the protein.

The second protein studied was $\alpha$-lactalbumin. Figure 21 shows the electropherogram of $\alpha$-lactalbumin at 6 different temperatures. A sharp peak was observed at low temperatures, broadened with increasing temperature, and eventually became sharp again at $50{ }^{\circ} \mathrm{C}$. When the mobility of the $\alpha$-lactalbumin was corrected for changes in viscosity, the mobility was found to decrease with increasing temperature. The authors concluded that this decrease in mobility was due to the increase in hydrodynamic volume that accompanied the thermal denaturation of the protein. 


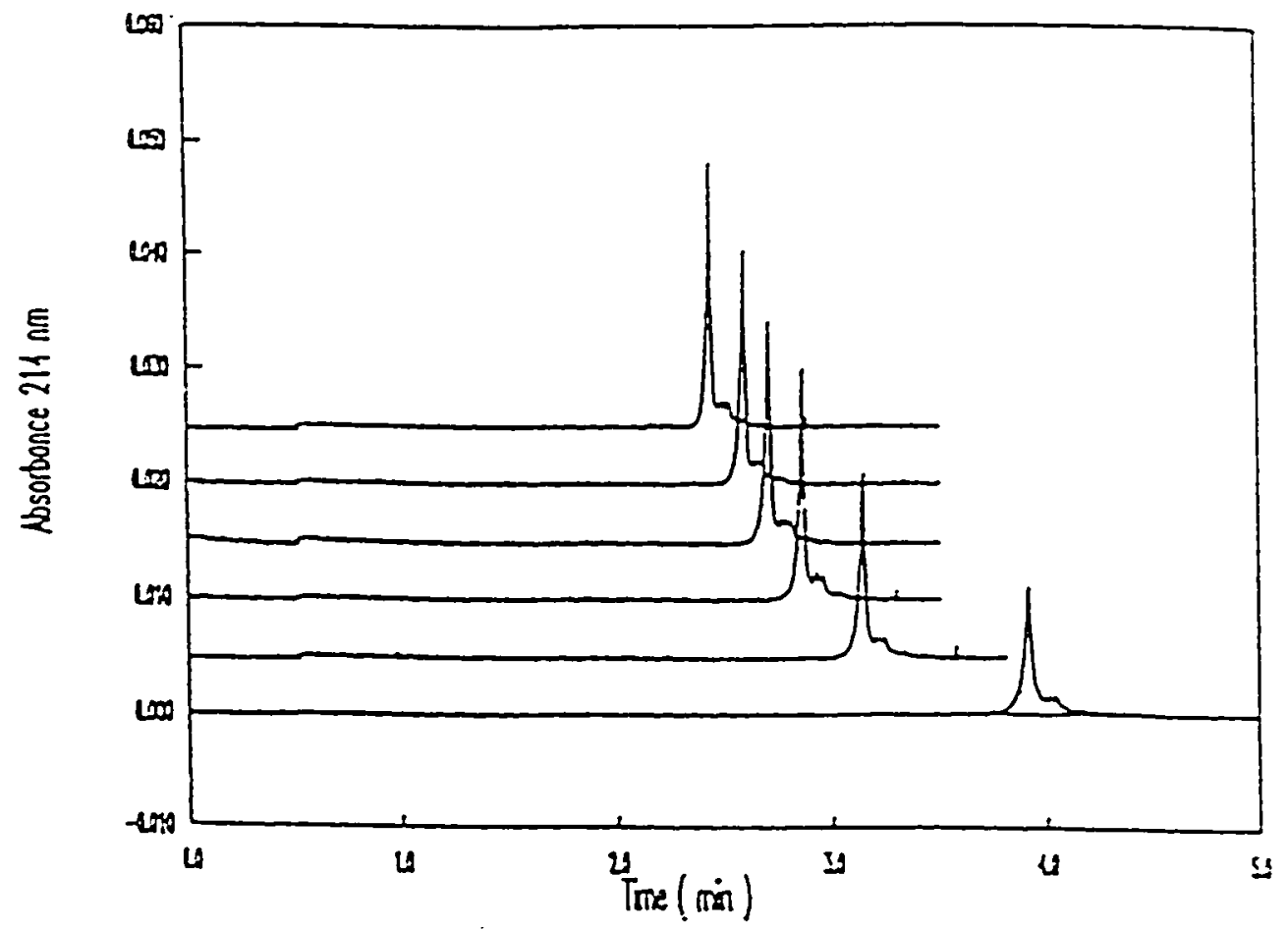

Figure 20: Electropherograms of horse heart myoglobin $(0.2 \mathrm{mg} / \mathrm{ml})$ at $20,30,45,40,45$ and $50{ }^{\circ} \mathrm{C}$ (ascending order) at a field of $350 \mathrm{~V} / \mathrm{cm}$ (reproduced with permission from Rush, R. S.; Cohen, A. S.; Karger, R. M. Anal. Chem. 1991, 63, 1346, ๑ by the American Chemical Society). 


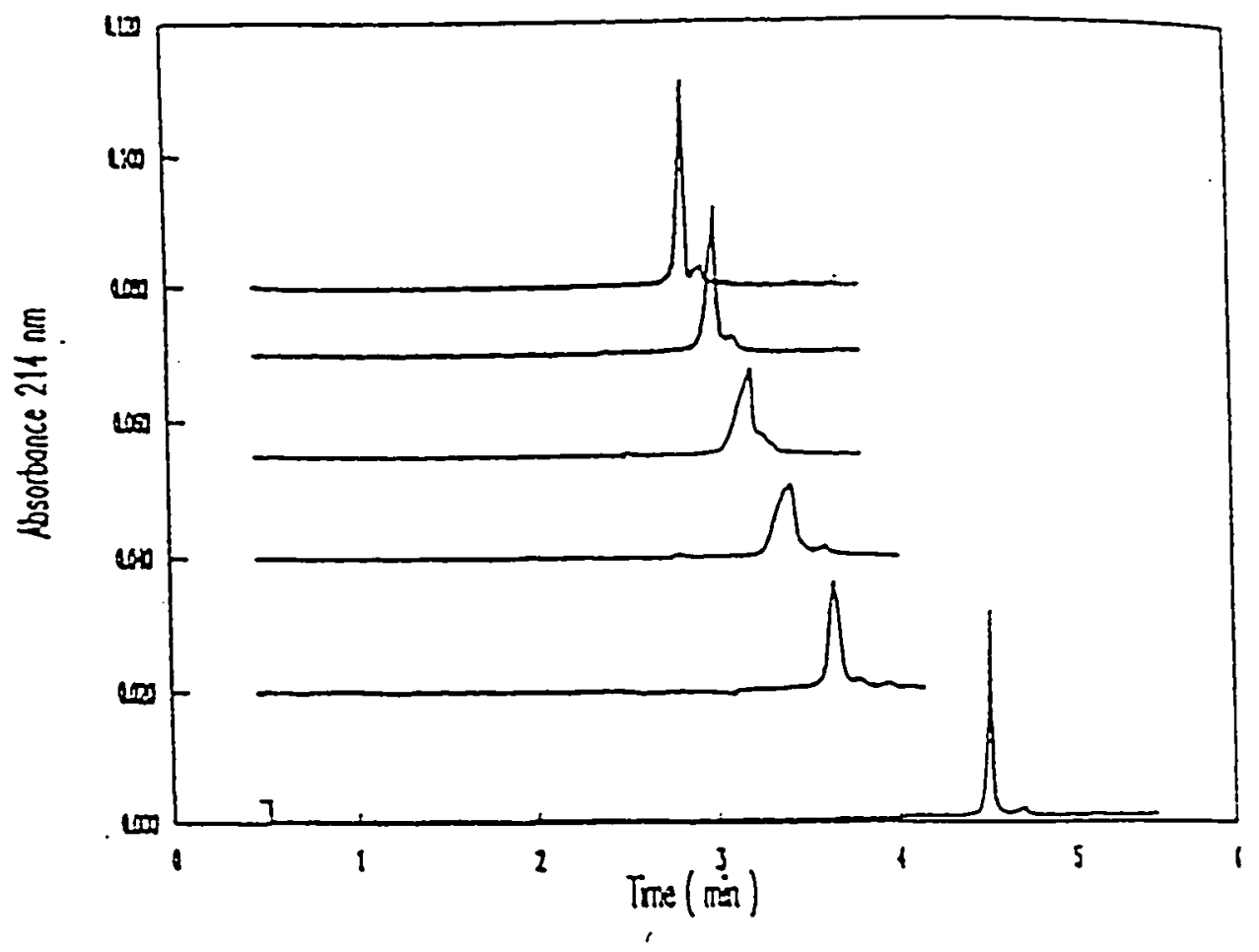

Figure 21: Comparison of the influence of temperature on the electrophoretic behavior of $\alpha$-lactalbumin $(0.2 \mathrm{mg} / \mathrm{ml})$ at $20,30,35,40,45$ and $50^{\circ} \mathrm{C}$ (ascending direction) at a field of $350 \mathrm{~V} / \mathrm{cm}$ (reproduced with permission from Rush, R. S.; Cohen, A. S.; Karger, R. M. Anal. Chem. 1991, 63, 1346, () by the American Chemical Society). 
1.7.1.2. Thermally induced protein folding / unfolding transition using free solution capillary electrophoresis (FSCE)

Hilser et al. examined the thermal unfolding of lysozyme and successfully showed that folding/unfolding can be observed by using HPCE. "2 Furthermore, as shown in Figure 22, a denaturation profile can be obtained by plotting the mobility against the temperature. The changes in mobility were used to estimate the apparent enthalpy change $\left(\Delta \mathrm{H}_{\mathrm{VH}}\right)$, entropy change (DS) and the transition temperature $\left(\mathrm{T}_{\mathrm{m}}\right)$, which compare well with calorimetric data (Table I). Thus, mobility of the native as well as the denatured protein provides a direct measure of the change in protein structure. This paper also points out that the shape of the electrophoretic peak can shed light on the population of intermediate states during the unfolding process. Figure 23 shows that as the temperature increases the peak shape of the lysozyme changes. At a low temperature, when the protein is in its native state, a sharp peak was observed whereas at a transition temperature, two rather broad peaks were observed in place of the sharp peak. This can be an indication of the presence of the native as well as the unfolded states. Furthermore. at a higher temperature only one sharp peak was observed which can be an indication of the unfolded state.

\subsection{Application of the diffusion method to study of protein folding}

Before discussing the feasibility of the diffusion method to study protein folding, it is important to understand the basic principle of the term diffusion. Let us imagine a solute molecule in a solution to which an external force $F_{i}$ is suddenly applied. An 


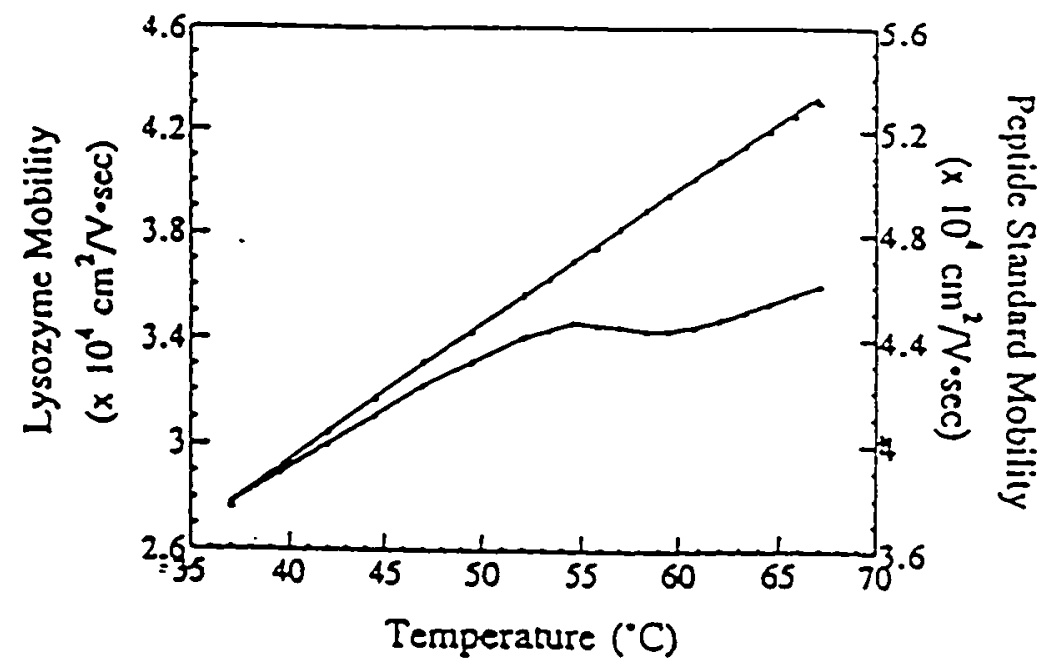

Figure 22: Electrophoretic mobility values obtained at various temperatures for the peptide standard RKRSRKE (closed triangles) and lysozyme (closed circles) (reproduced with permission from Hilser, V. J.; Worosila, G. D.; Freire, E. Anal. Biochem. 1993, 208, 125, (c) by the American Press). 
Table I: Comparison of FSCE and DSC

\begin{tabular}{|c|c|c|c|}
\hline Method & $\operatorname{Tm}\left({ }^{\circ} \mathrm{C}\right)$ & $\Delta \mathrm{H}_{\mathrm{VH}}(\mathrm{kcal} / \mathrm{mol})$ & $\Delta \mathrm{S}\left(\mathrm{cal} / \mathrm{K}^{*} \mathrm{~mol}\right)$ \\
\hline FSCE & 57.5 & 99.6 & 301 \\
\hline DSC & 56.3 & 98.9 & 300 \\
\hline
\end{tabular}




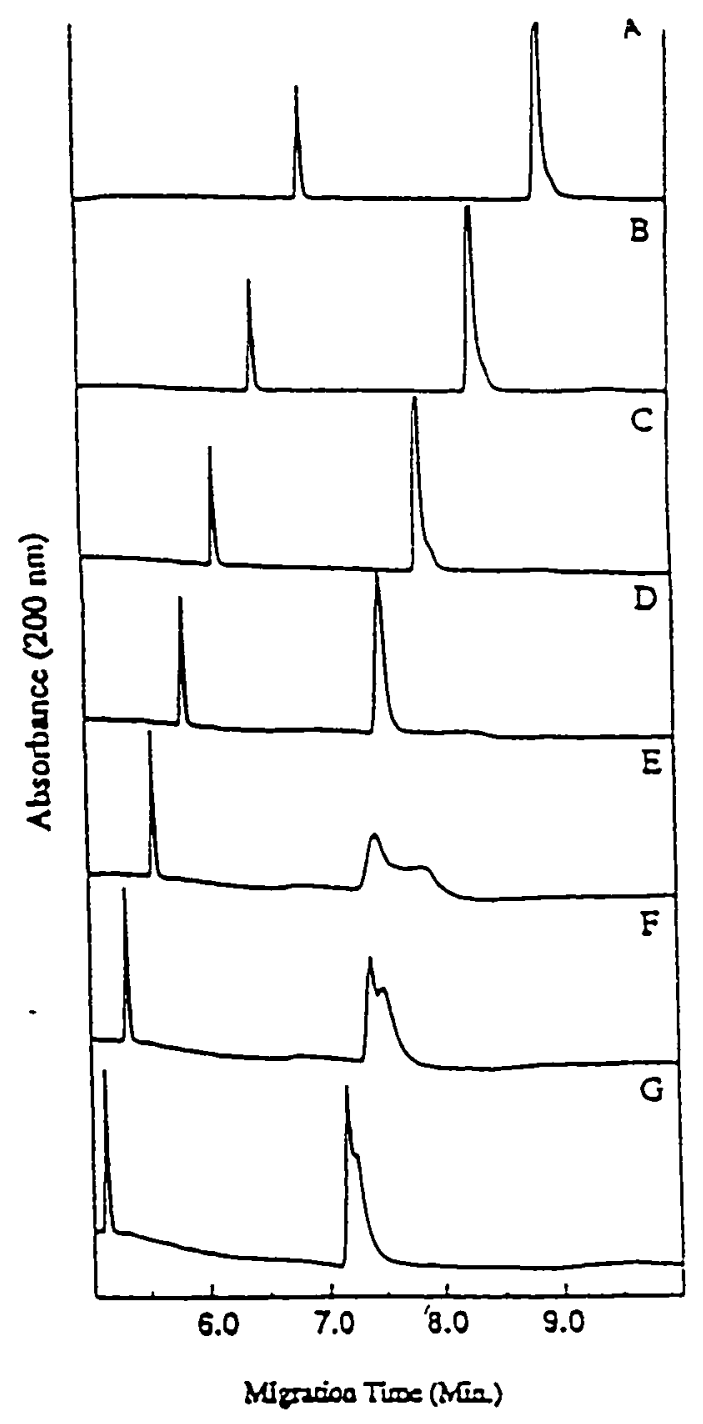

Figure 23: Capillary electropherograms of lysozyme at (A) $37^{\circ} \mathrm{C}$, (B) $42^{\circ} \mathrm{C}$, (C) $47^{\circ} \mathrm{C}$, (D) $52^{\circ} \mathrm{C}$, (E) $57^{\circ} \mathrm{C},(\mathrm{F}) 62^{\circ} \mathrm{C}$, and (G) $67^{\circ} \mathrm{C}$. The first peak corresponds to the peptide mobility standard (RKRSRKE) and the second peak is lysozyme (reproduced with permission from Hilser, V. J.; Worosila, G. D.; Freire, E. Anal. Biochem. 1993, 208, 125, (C) by the American Press). 
electric field might be switched on or a centrifugal force imposed by spinning the solution. Whatever the random motion may be, the molecule will also now be accelerated in the direction of the field. But this acceleration will last for only an exceedingly short time, for as its velocity increases, the molecule will experience an increasing frictional resistance to motion through medium. This frictional force will be given by $f_{i} v_{i}$, where $v_{i}$ is the velocity and the constsnt $f_{i}$ is called frictional coefficient of the molecule. ${ }^{23}$ A constant velocity will be reached when the total force on the molecule is zero.

$$
f_{i} v_{i}-F_{i}=0
$$

Thus, if one can measure the velocity of motion produced by a known force, one can determine the frictional coefficient. This frictional coefficient depends upon the size and shape of the molecule. The frictional resistance arises because solvent must flow around the moving object, and energy must be expanded due to the viscocity of the fluid. The calculation of frictional coefficients is a difficult exercise in hydrodynamic theory, and exact expressions have been obtained for only a few simple particle shapes. For example, for a sphere of radius $R$ can be calculated by using Stoke's law

$$
f_{0}=6 \pi \eta R
$$

where $\eta$ is the viscosity of the medium. It has been shown that for a given particle volume, the sphere has a minimum frictional coefficient $f_{0}$. To compare any of the other particles with a shape other than a sphere, a ratio of the frictional coefficient of that particle to the ideal sphere is often employed. Thus, for the ideal sphere $f / f_{0}$ is equal to one and for the shape other than the sphere the ratio of $f / f_{0}$ is greater than or equal to one. The same concept can be applied to proteins. In most of the native globular proteins. 
the ratio of is found to be 1.05 to 1.38 . As the unfolding process progresses, the shape of the protein no longer remains globular, but it becomes more like random coil. As a result the $f / f_{0}$ ratio increases due to unfolding.

Furthermore, molecules in a solution are not static at normal temperature, but undergoes a variety of movements that are primarily rotational and transitional in nature. Translational movement is characterized by the diffusion coefficient $D$ which is a measure of the concentration gradient $(\delta C / \delta x)$ of the substance with time $(\mathrm{t})$

$$
\left(\frac{\delta C}{\delta t}\right)=D\left(\frac{\delta^{2} C}{\delta x^{2}}\right)
$$

Furthermore, the diffusion coefficient is related to the frictional coefficient as follows

$$
f=\frac{K_{B} T}{D}
$$

where $f$ is the frictional coefficient, $K_{B}$ is the Boltzmann's constant and $T$ is the absolute temperature.

At any time $t$, the frictional coefficient $f_{t}$ can be written as follows

$$
f_{1}=\left(\frac{K_{B} T}{D_{t}}\right)
$$

and

$$
f_{1}=\alpha \eta_{t} r_{1}
$$

where $\alpha$ is the proportionality constant and $r$ is the hydrodynamic radius of the protein. Thus, by combining equations 20 and 21 , 


$$
\alpha \eta_{1} r_{t}=\frac{K_{B} T}{D_{t}}
$$

Rearranging equation 22 we get,

$$
D_{1}=\frac{K_{B} T}{\alpha \eta_{t} r_{t}}
$$

Equation 23 shows that the diffusion coefficient is a function of the viscosity as well as the hydrodynamic radius of the protein.

Many methods have been employed to calculate the diffusion coefficient and the value of $f / f_{0}$. Bournia et al. conducted extensive studies using the Taylor-Aris diffusion method and showed that it is possible to calculate the diffusion coefficient of the solute in a small tube. ${ }^{24}$ The following section describes the Taylor-Aris diffusion method in detail and discusses the importance of the frictional coefficient in protein folding.

\subsubsection{Taylor-Aris Diffusion Measurements}

When a soluble substance is introduced into a fluid flowing slowly through a small-bore tube, it spreads under the combined action of molecular diffusion and the variation of velocity over the cross section. ${ }^{25}$ Taylor discusses an approximation method for the case where radial molecular diffusion is important. He observed that for viscous flow, the solute was dispersed with an apparent diffusion coefficient of $a^{2} U^{2} / 48 D$ where $a$ is the radius of the tube, $U$ is the mean velocity of flow and $D$ is the molecular diffusion coefficient. In a later paper, Taylor showed that the conditions under which the approximate solution was valid for laminar flow with radial diffusion could be expressed 
as $+L / a>>U a / D>>6.9$ where $L$ is the length of the tube over which appreciable changes in concentration occur. ${ }^{26}$ On the basis of this, Aris showed that for tubes with noncircular cross-section, the dispersion coefficient is $D+\left(K a^{2} U^{2} / D\right)$ where $K$ is a constant dependent upon the shape of the tube. ${ }^{27}$ More recently, Bello et al. showed that the diffusion coefficient can be easily calculated by a simple experiment using diffusion in a HPCE instrument. 28

\subsubsection{Application of the Taylor-Aris method to protein folding}

The Taylor-Aris method provides a relatively easy method to get extensive information about the protein's hydrodynamic parameters. Thus, with the help of this method, one can calculate the diffusion coefficient, which is in turn proportional to the $f / f_{0}$ ratio.

Since the frictional ratio $f / f_{0}$ is a direct measurement of the size, it follows that the unfolding of a protein can be monitored as a function of temperature. Recently it has been seen that, thin fused silica capillaries ( $50 \mu \mathrm{m}$ to $100 \mu \mathrm{m}$ of inner diameter) can be used to obtained fast measurements of the diffusion coefficients without the need for any special precautions. ${ }^{29}$ Thus, one can calculate the diffusion coefficient of the solute by using commercially available narrow bore fused silica capillaries and a standard instrument of capillary electrophoresis with a UV detector. (The detailed calculations are presented in the experimental section.) 


\subsubsection{Using a combination of electrophoretic mobility and diffusion measurements in}

\section{the study of protein folding}

Protein folding can be studied with the help of the capillary electrophoresis instrument using either capillary zone electrophoresis or the diffusion method. This is beneficial because the results can be examined by two independent methods.

Electrophoresis involves the motion of the charged particles in the solution under the influence by the electric field. When the charged particle is placed in an electric field, it experiences a force $F_{\text {elec, }}$ which is proportional to its net charge $q$ and the electric field strength $E$,

$$
F_{\text {elec }}=q * E
$$

Along with the electric force, the particle also experiences a drag force $F_{\text {drag }}$ which is proportional to the particle velocity $v$,

$$
F_{\text {drag }}=f * v
$$

where the proportionality constant $f$ is called the frictional coefficient. Thus, the equation describing the translational motion of a particle under the influence of an electric field is,

$$
F_{\text {tot }}=F_{\text {ele }}-F_{\text {drag }}=q E-f v
$$

When the particle reaches its steady state velocity $v_{s s}, F_{t o t}=0$, and equation 26 reduces to

$$
v_{s s}=\frac{q E}{f}
$$

Since $\mu_{e}=\frac{v}{E}$, 


$$
\mu_{e}=\frac{q}{f}
$$

Thus, by performing the electrophoretic and diffusion methods, more information about protein folding process can be obtained. Since the electrophoretic mobility is a function of the ratio of the charge on the protein to its frictional coefficient and the diffusion method yields the ratio of $f / f 0$ with respect to the unfolding process, we can study the folding process with its electrophoretic as well as hydrodynamic parameters. ${ }^{30}$

\subsection{RNase $A$ as a model for protein folding}

Ribonuclease A (RNase A) was used as a model protein to accomplish the goals of this project. RNase A is a small globular protein that catalyzes the hydrolysis of ribonucleic acid. RNase A consists of a single polypeptide chain of 124 amino acid residues with four disulfide linkages, four proline residues and six tyrosine residues. Three of the tyrosine residues are exposed to the solvent while the other three are buried inside the hydrophobic core. The X-ray crystallographic native structure of RNase A shows that the protein consists of two subdomains. As the protein unfolds, the tyrosine residues from the core become exposed to the solvent resulting in a change in the protein spectral or hydrodynamic properties. It has been observed that RNase A undergoes reversible unfolding without losing its activity. Furthermore, RNase A is a very hydrophilic protein and tends not to aggregate even in the unfolded state. Thus, RNase A serves as an excellent model protein. 


\section{MATERIALS AND METHODS}

\subsection{Materials}

Bovine pancreatic ribonuclease A was purchased from Sigma Chemicals Company, St. Louis, MO. All the other reagents used in the experiments were purchased from Fisher scientific and were reagent grade.

\subsection{Purification of RNase A}

RNase A was purified on a Sephadex SPS-25 ion exchange column $(i .5 \times 25 \mathrm{~cm})$ using phosphate buffer at $\mathrm{pH} 6.5^{29} 150 \mathrm{mg}$ RNase $\mathrm{A}$ was dissolved in 1 to $2 \mathrm{~mL}$ of the phosphate buffer and loaded onto a pre-equilibrated column. The elution was carried out at room temperature. This procedure serves to separate monomeric RNase A from aggregates and RNase S. The purified RNase A was then dialyzed against $25 \mathrm{~L}$ of deionized water for 8 to 10 hours. The final product was frozen, lyophilized and stored at $-20^{\circ} \mathrm{C}$

\subsection{Buffer preparation}

\subsubsection{Preparation of formate buffer}

$10 \mathrm{mM}$ of formate buffer was prepared by mixing appropriate amounts of $1 \mathrm{M}$ formic acid and $1 \mathrm{M} \mathrm{NaOH}$ to give a $\mathrm{pH}$ of 3.00 . Initial results showed that the current generated by using $10 \mathrm{mM}$ formate buffer was too low to perform the electrophoresis (approximately 5-6 $\mu \mathrm{A}$ ), besides which the peak shape was very broad with considerable tailing. To avoid this problem, potassium chloride $(\mathrm{KCl})$ was added in the buffer. 
Potassium chloride was chosen because of its minimal effect on the stability of RNase A. Several concentrations of $\mathrm{KCl}$ were tried. Finally the buffer was made by dissolving 10 $\mathrm{mM}$ formate buffer and proper amount (about $90 \mathrm{mM}$ ) of $\mathrm{KCl}$, to give a final concentration of $100 \mathrm{mM}$. The final current during the electrophoresis was 40 to $50 \mu \mathrm{A}$.

\subsubsection{Preparation of acetate buffer}

$100 \mathrm{mM}$ of acetate buffer was prepared by mixing appropriate amounts of $1 \mathrm{M}$ glacial acetic acid, $1 \mathrm{M} \mathrm{NaOH}$ and $\mathrm{KCl}$ to give a $\mathrm{pH}$ of 4.5 .

\subsection{Preparation of the protein sample}

The $\mathrm{pI}$ of the RNase $\mathrm{A}$ is around 9.8. To maintain the $\mathrm{pH}$ of the sample and the running buffer at equal values, $22 \mathrm{mM}$ of $\mathrm{RNase} A$ was prepared by dissolving $0.3 \mathrm{mg}$ of RNase $\mathrm{A}$ in $1 \mathrm{~mL}$ of deionized water. The $\mathrm{pH}$ of the solution was further adjusted to 3.00 and 4.50 respectively. The solution was then lyophilized and reconstituted in the respective buffers to the same concentration as that of the buffers. The final $\mathrm{pH}$ was checked and found to be 3.00 and 4.50 respectively.

\subsection{Electrophoresis}

\subsubsection{Experimental conditions}

All electrophoretic experiments were performed using a Hewlett-Packard

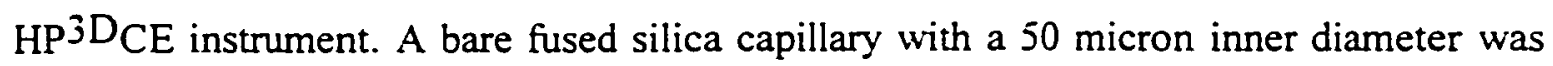
used. The length of the capillary was $72 \mathrm{~cm}$ total and $65.5 \mathrm{~cm}$ to detector. The capillary 
was preconditioned before performing the experiment to insure reproducible results.

A fresh capillary was first washed with $1 \mathrm{~N} \mathrm{NaOH}$ for 5 minutes followed by 0.1 $\mathrm{N} \mathrm{NaOH}$ for 30 minutes. Generally, it is recommended that the capillary be washed with $0.1 \mathrm{~N} \mathrm{NaOH}$ between runs. Due to the hystersis effect described in the introduction, this treatment was avoided in our experiments. Instead of using $\mathrm{NaOH}$, the capillary was first washed with $0.1 \mathrm{~N}$ nitric acid for 1 minute. This was followed by washing the capillary with of deionized water for 1 minute and finally a 5 minute wash with the running buffer. The above preconditioning steps were performed before each run in all our experiments. The sample injection was accomplished by applying 50 mbar pressure at the injection end for 10 seconds. Electrophoretic experiments were performed as follows.

A constant voltage of $20 \mathrm{kV}$ was applied for sucessively for seven times at a fixed temperature. The temperature was ramped up from $15{ }^{\circ} \mathrm{C}$ to $60{ }^{\circ} \mathrm{C}$ keeping the temperature constant for a single run. The data was collected at intervals of $5^{\circ} \mathrm{C}$ before and after the transition, and steps of $1{ }^{\circ} \mathrm{C}$ during the transition. Since multiple wavelengths could be observed with the $\mathrm{HP}^{3 \mathrm{D}} \mathrm{CE}$ instrument, absorbance data was collected at $200 \mathrm{~nm}, 254 \mathrm{~nm}$ and $286 \mathrm{~nm}$ for each temperature examined. The entire experiment was repeated for $\mathrm{pH} 4.5$ by using $100 \mathrm{mM}$ acetate buffer containing $\mathrm{KCl}$.

A UV detector was used for electrophoresis. With the help of the detector. multiple wavelengths could be detected at the same time. The observed wavelengths were $214 \mathrm{~nm}, 254 \mathrm{~nm}$ and $286 \mathrm{~nm}$. Since the values of the absorbance were obtained during the electrophoretic experiment, a separate experiment was not necessary. A graph of absorbance verses temperature was plotted for both the $\mathrm{pH}$ values. 


\subsubsection{Calculation of the injected sample volume}

In all the above experiments the sample was injected hydrodynamically. Hydrodynamic sample injection is the most widely used method. It is accomplished by an application of pressure at the injection end of the capillary. The volume of the loaded sample is the function of the capillary dimensions, the viscosity of the buffer in the capillary, the applied pressure and the time. The volume injected can be calculated from the Hagen-Poiseuille equation.

$$
\text { Sample volume injected }=\frac{\Delta P d^{4} \pi t}{128 \eta L}
$$

Where

$$
\begin{aligned}
& \Delta P=\text { pressure difference across the capillary. } \\
& d=\text { capillary inner diameter } \\
& t=\text { time } \\
& \eta=\text { buffer viscosity } \\
& L=\text { total length of the capillary }
\end{aligned}
$$

Note that as the temperature increases, the volume injected into the capillary also increases and as such it is important to keep the injection plug as small as possible. Precise temperature control $\left( \pm 0.1^{\circ} \mathrm{C}\right)$ of the capillary is necessary to maintain constant injection volume. Furthermore, sample viscosity does not affect injection volume if the sample plug is very small $(0.2$ to $0.6 \mathrm{~nL})$ as compared to the total liquid volume in the capillary. 


\subsubsection{Calculations for the mobility of RNase $A$ at a particular temperature.}

The time required for a solute to migrate to the point of detection is called the migration time. The migration time is a function of the capillary length and the velocity of the solute. The migration time and other parameters are used to calculate the apparent solute mobility $\left(\mu_{a}\right)$ using the following equation.

$$
\mu_{a}=\frac{l}{t E}=\frac{l L}{t V}
$$

where

$$
\begin{aligned}
& \mu_{a}=\mu_{\text {epm }}+\mu_{\text {eof }} \\
& \mu_{\text {epm }}=\text { electrophoretic mobility } \\
& \mu_{\text {eof }}=\text { electroosmotic flow } \\
& V=\text { applied voltage } \\
& l=\text { effective length of the capillary to the detector } \\
& L=\text { total length of the capillary } \\
& t=\text { migration time } \\
& E=\text { electric field }
\end{aligned}
$$

The EOF was calculated with the help of a neutral maker dimethyl sulfoxide (DMSO). $0.1 \%$ DMSO was injected by applying 50 mbar of pressure for 3 seconds, and the electrophore $i s$ was then carried out at constant voltage. After 8 hours, a DMSO peak was observed. The mobility of DMSO was calculated and found to be small enough to be ignored. Since the $\mu_{\text {eof }}$ is close to zero, the mobility of RNase A at any particular temperature can be written as follows:

$$
\mu_{a}=\mu_{e p m}
$$




\subsection{Diffusion experiments}

\subsubsection{Experimental conditions}

$0.3 \mathrm{mg} / \mathrm{mL}$ of RNase A was prepared as described above in the formate buffer of $\mathrm{pH}$ 3.00. The capillary was first washed with $0.1 \mathrm{M} \mathrm{HNO}_{3}$ followed by washing with the running buffer for 3 minutes. The sample was then injected for 10 seconds into a capillary filled with the buffer solution. The sample was injected by inserting the edge of the capillary in the sample vial and lifting the edge for $10 \mathrm{sec}$. Then the plug of the running buffer was injected for 2 seconds. This procedure was followed by returning the edge of the capillary to the vial containing the buffer. A pressure drop of 50 mbars was applied at the end of the capillary. The solute slowly flowed through the capillary to the UV detector that was positioned at a distance $l$ from the injection point. The sample was diffused across the capillary and a guassian shape peak was observed. In order to calculate the area under the guassian peak, a blank run was carried out without injecting the sample. The Sigma Plot ${ }^{\mathrm{TM}}$ was used to calculate the area under the guassian curve as described in the following section. The data obtained from the Sigma Plot ${ }^{\text {TM }}$ was further analyzed in an Excel spreadsheet. The entire experiment was repeated for $\mathrm{pH} 4.5$ by using $100 \mathrm{mM}$ acetate buffer containing $\mathrm{KCl}$.

\subsubsection{Diffusion coefficient calculations for RNase A with Taylor-Aris Dispersion}

\section{Measurements.}

The diffusion coefficient of any solute molecule can be calculated by using the dispersion of a solute plug in a laminar Poiseuille flow. ${ }^{25}$ Taylor's analysis leads to the 
conclus: on that, ${ }^{26}$ the mass flux $Q$ along the tube axis may be represented as a sum of a convective part and a diffusion part given by Fick's law with an apparent diffusion coefficient $D^{*}$

$$
Q=U C_{m}+D^{\cdot} \frac{\partial C_{m}}{\partial x}
$$

where $Q$ mass flux along the tube axis

$U=$ mean velocity

$C_{m}=$ mean analyte concentration over the tube cross section

$x=$ distance along the axis

The apparent diffusion coefficient $D^{*}$ is related to the molecular diffusion coefficient as follows

$$
D^{*}=D+\frac{R^{2} U^{2}}{48 D}
$$

where

$$
D=\text { coefficient of molecular diffusion }
$$

$$
R=\text { tube radius }
$$

The absorbance of the solute plug was detected by UV detector at $200 \mathrm{~nm}$ giving an elution profile $C(t)$ where $C$ is the amplitude of the signal and $t$ is the time. The elution profile was analyzed with the help of Sigma Plot ${ }^{\mathrm{TM}}$, by which the zero moments $\mathcal{L}_{o}$ and normalized first $m_{l}$ and second $m_{2}$ moments were calculated according to following equations.

$$
M_{0}=\int_{b}^{\infty} C(t) d t
$$




$$
\begin{aligned}
& m_{l}=\frac{1}{M_{0}} \int_{b}^{\infty} C(t) t d t \\
& m_{2}=\frac{1}{M_{0}} \int_{b}^{\infty} C(t)\left(t-m_{1}\right)^{2} d t
\end{aligned}
$$

According to the Taylor-Aris theory, the distribution of the mean concentration over the capillary axis becomes Gaussian. For a Gaussian profile, the time moments are related to the dispersion coefficients as follows

$$
\begin{aligned}
& m_{l}=\frac{l}{U}+\frac{2 D^{\circ}}{U^{2}} \\
& m_{2}=\frac{2 D^{\circ}}{U^{3}} l+\frac{8 D^{\circ}}{U^{4}}
\end{aligned}
$$

These equations allow for determination of both $\frac{l}{U}$ and $\mathrm{D}^{*}$ as

$$
\begin{aligned}
& \frac{l}{U}=\frac{m_{1}}{2}\left(3-\sqrt{1+\frac{4 m_{2}}{m_{1}^{2}}}\right) \\
& D^{*}=\frac{1}{2} U^{2}\left(m_{1}-\frac{l}{U}\right)
\end{aligned}
$$

Multiplying equation 33 by $D$,

$$
D D^{\cdot}=\frac{D^{2}+R^{2} U^{2}}{48}
$$

Rearranging the equation,

$$
D^{2}-D D^{\cdot}+\frac{R^{2} U^{2}}{48}=0
$$


Hence, $D$ can be calculated by solving a quadratic equation ( equation 42 ). The solution of the equation gives two values for $D$, one that is greater than $D^{\circ}$ and one which is less than $D^{\circ}$. Since the value of $D^{*}$ is a sum of the value of $D$ and $R^{2} U^{2} / 48, D$ must always be smaller than $D^{*}$. Thus, only one value is valid for the calculations.

At $15^{\circ} \mathrm{C}, \mathrm{RNase} \mathrm{A}$ is in its native form and for simplicity we consider $f_{o}$ as the frictional coefficient at $15^{\circ} \mathrm{C}$. Then, with the help of the value of $f_{0}$ and $f$ (where $f$ is the value of the frictional coefficient at that temperature), a ratio of $f / f 0$ was obtained for each temperature. To observed the unfolding of RNase A with respect to the frictional coefficient ratio, the values of $f / f 0$ were plotted against the temperature.

\subsubsection{Determination of transition midpoint $\left(T_{m}\right)$}

Although a definite mechanism and pathway of protein folding are not very clear. often the data can be analyzed by considering a two-state model. This model assumes that the protein exists in an equilibrium between the native state $(N)$ and the denatured state (D), and the concentrations of the intermediates are low enough to ignored. ${ }^{27}$

$$
N \Leftarrow \Rightarrow D
$$

If the folding mechanism is complicated by the presence of an intermediate state. the denaturation curve can not be analyzed by above method.

A typical denaturation curve shown in Figure 25 is composed of three parts: pretransition, transition, and posttransition regions. As temperature increases ( $\mathrm{X}$ axis), any 
observable parameter ( $\mathrm{Y}$ axis) that measures the protein folding process changes. These parameters are either mobility, absorbance, or the $f / f_{0}$ ratio.

In order to compare the data obtained by different methods, the data is usually standardized. The method frequently employed assumes that the signal changes in both the pre- and posttransition regions reflect a solvent effect on the native and denatured states and only the transition region contains information about unfolding process. A single value for the native state $(1 / N)$ and the denatured state $(1 / D)$ can be obtained at the pretransition and posttransition regions, respectively. The amplitude of the unfolded state in the transition region is given by,

$$
y=f_{N} y_{N}+f_{D} y_{D}
$$

where the values of $y_{v}$ and $y_{D}$ are obtained at each point by extrapolation from the linear portion of the pretransition and the posttransition regions. $f_{N}$ and $f_{D}$ represent the fraction of the protein in the native and denatured states, respectively.

Since the sum of $f_{V}$ and $f_{D}$ must be unity,

$$
y=y_{. v}+f_{D}\left(y_{D}-y_{. v}\right)
$$

And thus,

$$
f_{D}=\frac{\left(y-y_{. v}\right)}{\left(y_{D}-y_{. v}\right)}
$$

The transition midpoint, $T_{m}$, is defined as the temperature in the transition region where the values of $f_{\mathrm{v}}$ and $f_{D}$ are equal. Thus, by solving the above equation, the $\mathrm{T}_{\mathrm{m}}$ value for protein folding can be determined. 


\section{RESULTS}

\subsection{Thermal Denaturation of RNase A}

The temperature-mediated denaturation of RNase A was examined over a temperature range of $15^{\circ} \mathrm{C}$ to $60^{\circ} \mathrm{C}$. The unfolding transitions were monitored by electrophoresis and the Taylor-Aris diffusion method at both $\mathrm{pH} 3.00$ and $\mathrm{pH} 4.5$. All measurements were obtained using a UV detector at multiple wavelengths of $200 \mathrm{~nm}$. $245 \mathrm{~nm}$ and $286 \mathrm{~nm}$. The absorbance at $286 \mathrm{~nm}$ provided an absorbance monitor for the thermal denaturation. The results are compared in Table II.

\subsubsection{Examination of the denaturation of RNase A monitored by electrophoretic} mobility and absorbance using formate buffer at $\mathrm{pH} 3.00$

The absorbance at $286 \mathrm{~nm}$ for RNase A measured in the detector during electrophoresis as a function of temperature is shown in Figure 24. The decrease in absorbance is characteristic for the denaturation of this protein and gives a transition midpoint of $45.1^{\circ} \mathrm{C}$.

Figure 25 shows the electrophoretic mobility of RNase $A$ as a function of temperature. The results show a linear increase in mobility below $35^{\circ} \mathrm{C}$ and above $52^{\circ} \mathrm{C}$. Since no change in the absorbance at $286 \mathrm{~nm}$ is observed in these regions, it is assumed that the change in mobility is merely due to the decrease in viscosity associated with the increasing temperature. Between these temperatures, the mobility changes in three discrete steps. The mobility first levels off in the $35-42{ }^{\circ} \mathrm{C}$ range and then increases 
Table II: Comparision of Transition midpoints by various methods.

\begin{tabular}{|c|c|c|c|c|c|c|}
\hline \multirow[t]{2}{*}{$\begin{array}{l}\text { Method } \\
\text { used }\end{array}$} & \multicolumn{3}{|c|}{$\begin{array}{l}\text { For } \mathrm{pH} 3.00 \text { (10mM formate }+ \\
100 \mathrm{mM} \mathrm{KCl} \text { buffer })\end{array}$} & \multicolumn{3}{|c|}{$\begin{array}{l}\text { For } \mathrm{pH} 4.50 \text { (10mM acetate }+ \\
100 \mathrm{mM} \mathrm{KCl} \text { buffer })\end{array}$} \\
\hline & $\begin{array}{l}\text { Pre } \\
\text { transition } \\
\left.{ }^{\circ} \mathrm{C}\right)\end{array}$ & $\begin{array}{l}\text { Major } \\
\text { transition } \\
\left.{ }^{\circ} \mathrm{C}\right)\end{array}$ & $\begin{array}{c}\text { Post } \\
\text { transition } \\
\left.{ }^{\circ} \mathrm{C}\right)\end{array}$ & $\begin{array}{l}\text { Pre } \\
\text { transition } \\
\left.\text { ( }{ }^{\circ} \mathrm{C}\right)\end{array}$ & $\begin{array}{l}\text { Major } \\
\text { transition } \\
\left.{ }^{\circ} \mathrm{C}\right)\end{array}$ & $\begin{array}{l}\text { Post } \\
\text { transition } \\
\left({ }^{\circ} \mathrm{C}\right)\end{array}$ \\
\hline $\begin{array}{l}\text { Mobility } \\
\left(\mathrm{cm}^{2} / \mathrm{V}^{*} \mathrm{sec}\right)\end{array}$ & 38 & $43.7(2.4)$ & $\begin{array}{l}\text { small change } \\
\text { at } 48-52\end{array}$ & 40 & 48.5 & $\mathrm{~T}_{\mathrm{m}} \mathrm{-NO}$ \\
\hline $\begin{array}{l}\text { Diffusion } \\
\left(\mathrm{cm}^{2} / \mathrm{sec}\right)\end{array}$ & $T_{m}-\mathrm{NO}$ & $43.3(3.4)$ & $48.5(0.25)$ & $\mathrm{T}_{\mathrm{m}}$-NO & $51.8(0.51)$ & $\mathrm{T}_{\mathrm{m}}-\mathrm{NO}$ \\
\hline $\begin{array}{l}\text { Absorbance } \\
(\mathrm{nm})\end{array}$ & $\mathrm{T}_{\mathrm{m}} \mathrm{-NO}$ & $45.1(0.62)$ & $\mathrm{T}_{\mathrm{m}}-\mathrm{NO}$ & 38 & $51.4(0.63)$ & $\mathrm{T}_{\mathrm{m}}-\mathrm{NO}$ \\
\hline
\end{tabular}

$\mathrm{T}_{\mathrm{m}}$-NO $=$ Transition midpoint for this data could not be determined. 


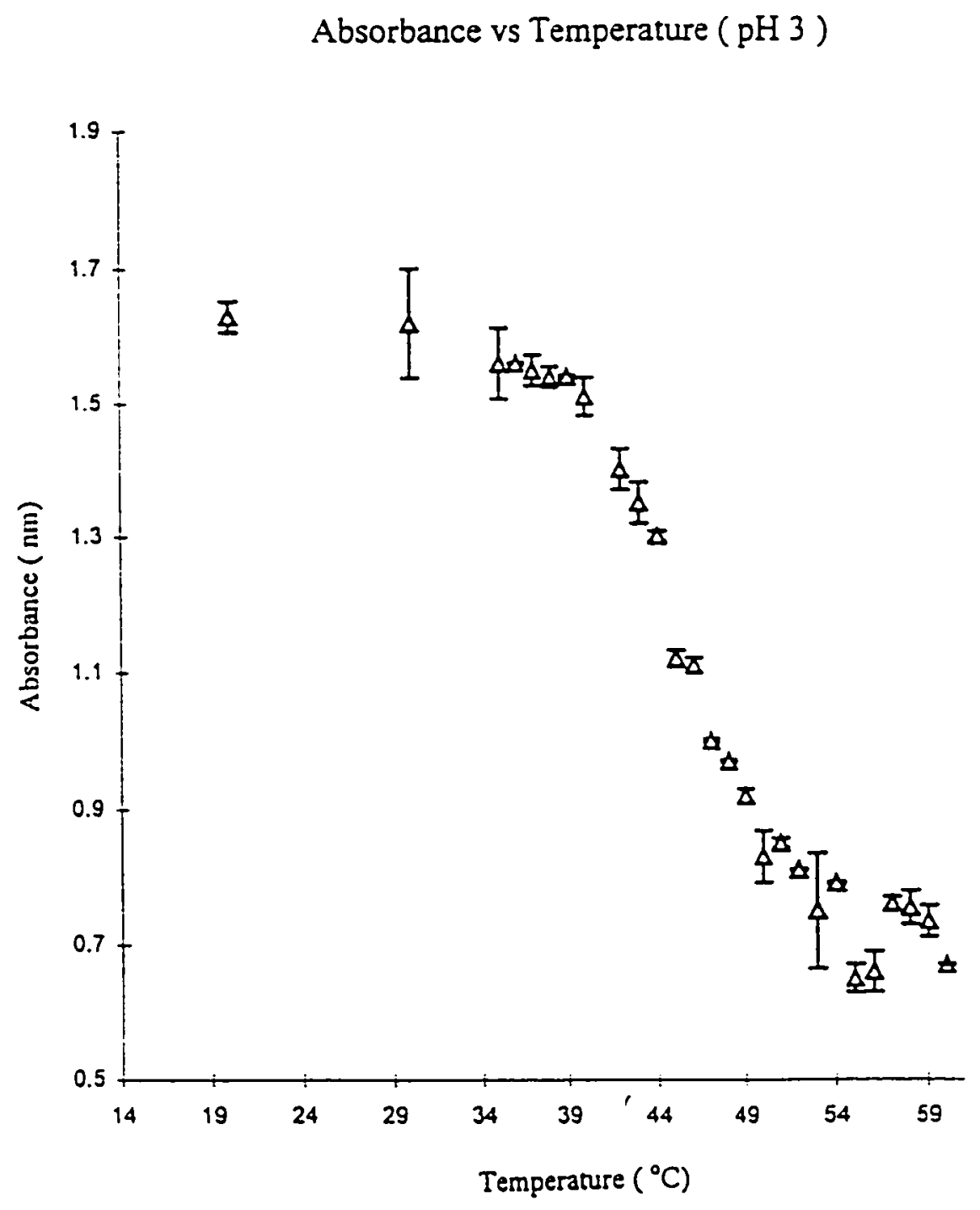

Figure 24: Thermal denaturation of $\mathrm{RNase} \mathrm{A}$ at $\mathrm{pH} 3.00$ with the help of absorbance method. Conditions: buffer used $10 \mathrm{mM}$ formate and $100 \mathrm{mM} \mathrm{KCl}, \mathrm{l}=57 \mathrm{~cm}, \mathrm{~L}=65.5$ $\mathrm{cm}$, capillary id $=50 \mu \mathrm{m}$. (The error bars represent standard deviation calculated for 7 experiments at each temperature.) 
Unfolding of RNase A ( $\mathrm{pH} 3$ )

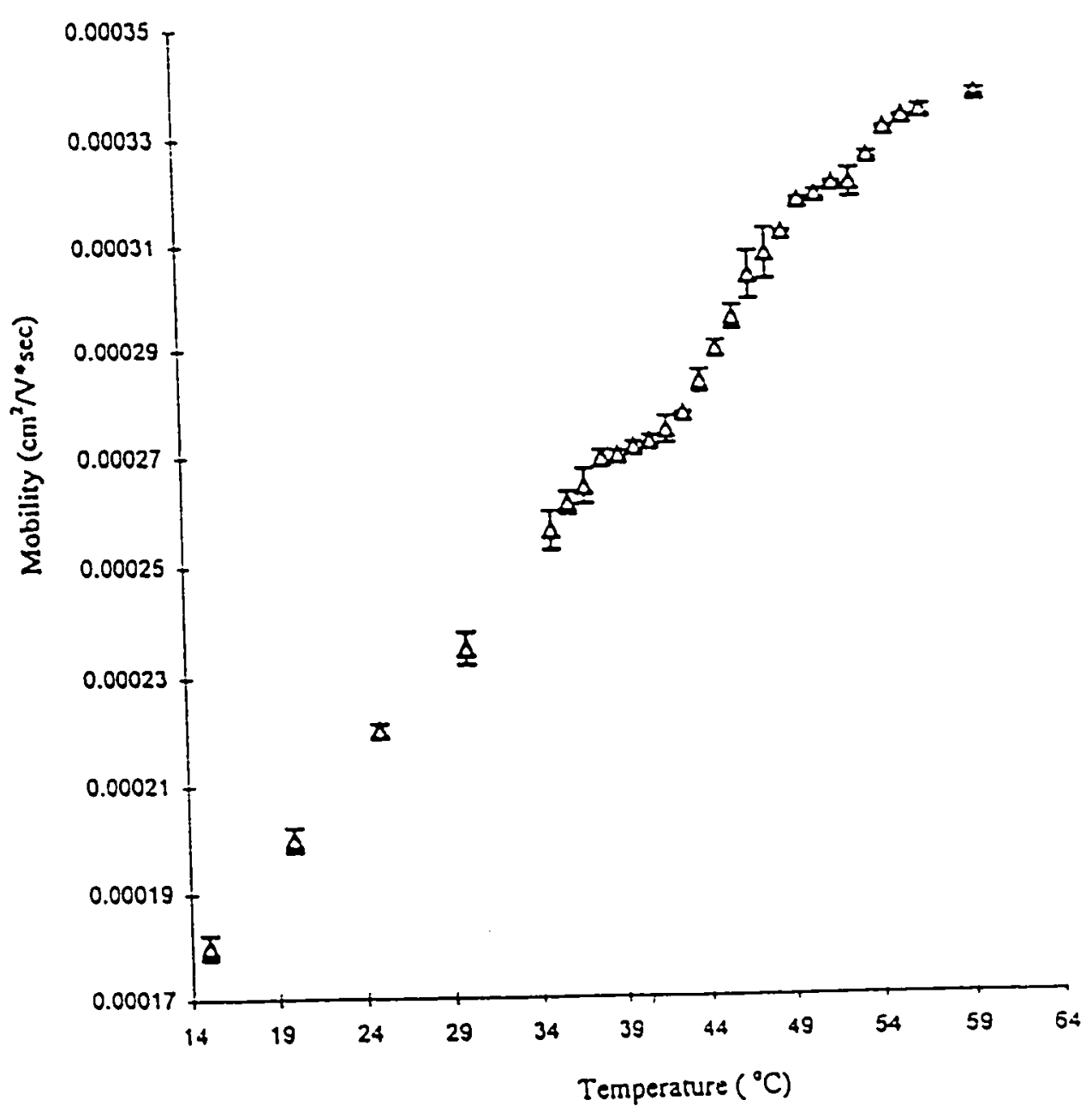

Figure 25: Thermal denaturation of $\mathrm{RNase} A$ at $\mathrm{pH} 4.50$ with the help of electrophoretic mobility. Conditions: buffer used $10 \mathrm{mM}$ acetate and $100 \mathrm{mM} \mathrm{KCl}, \mathrm{I}=57 \mathrm{~cm}, \mathrm{~L}=65.5$ $\mathrm{cm}$, capillary id $=50 \mu \mathrm{m}$. (The error bars represent standard deviation calculated for 7 experiments at each temperature.) 
markedly in a major and a minor step. Close inspection of the data reveals a midpoint of $43.7^{\circ} \mathrm{C}$ for the major mobility increase and a midpoint near $50{ }^{\circ} \mathrm{C}$ for the minor transition.

\subsubsection{Examination of the denaturation of RNase A by Taylor-Aris Diffusion Method} at pH 3.00

To confirm the validity of the mobility data, a second experiment was performed in which the denaturation of RNase A was examined with the diffusion coefficient, and the values of diffusion coefficients were calculated over the entire temperature range for both $\mathrm{pH}$ values. The diffusion coefficient was used to calculate a frictional coefficient $(f)$ (Equation 14) and a graph of the frictional ratio $\left(f / f_{\delta}\right)$ was plotted where $f_{0}$ is the frictional coefficient at $15^{\circ} \mathrm{C}$ as shown in Figure 26. The data shows an increase in the $f /$ $f_{o}$ ratio with increasing temperature. The largest change is observed in the $35-50{ }^{\circ} \mathrm{C}$ range and appears bimodal with transition midpoints of $43.3^{\circ} \mathrm{C}$ and $48.5^{\circ} \mathrm{C}$. The results compare quite favorably with those obtained from the electrophoretic mobility data.

\subsubsection{Examination of the denaturation of RNase $A$ by electrophoresis and} absorbance at pH 4.5 with acetate buffer

The absorbance at $286 \mathrm{~nm}$ for RNase A measured in the detector during electrophoresis as a function of temperature is shown in Figure 27. The decrease in 


\section{ftfo vs Temperature (pH 3 )}

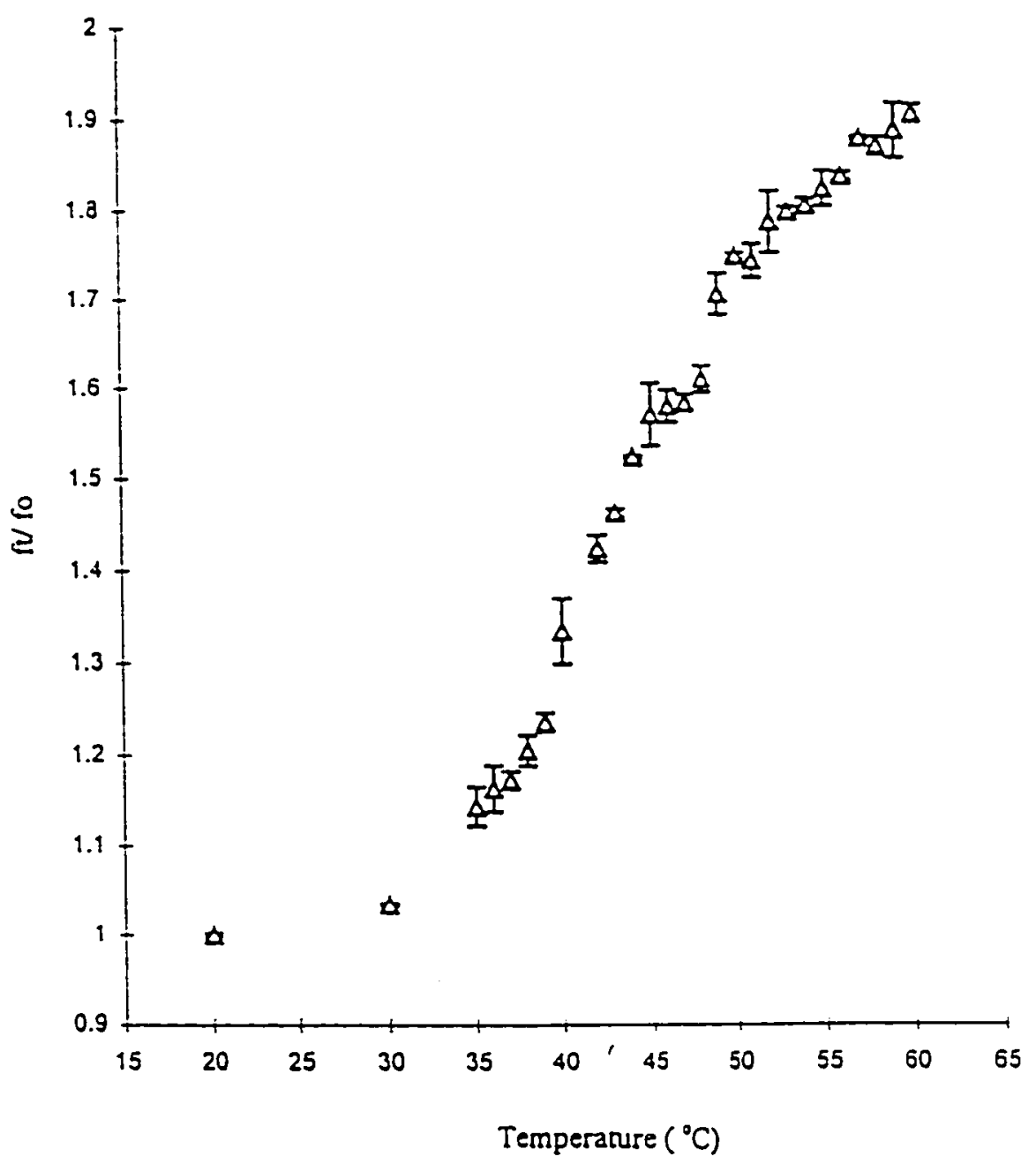

Figure 26: Thermal denaturation of $\mathrm{RNase} A$ at $\mathrm{pH} 3.00$ with the help of diffusion coefficient.methed. Conditions: buffer used $10 \mathrm{mM}$ formate and $100 \mathrm{mM} \mathrm{KCl}, 1=57 \mathrm{~cm}$, $\mathrm{L}=65.5 \mathrm{~cm}$, capillary id $=50 \mu \mathrm{m}$. (The error bars represent standard deviation calculated for 7 experiments at each temperature.) 
Absorbance vs Temperature (pH 4.5)

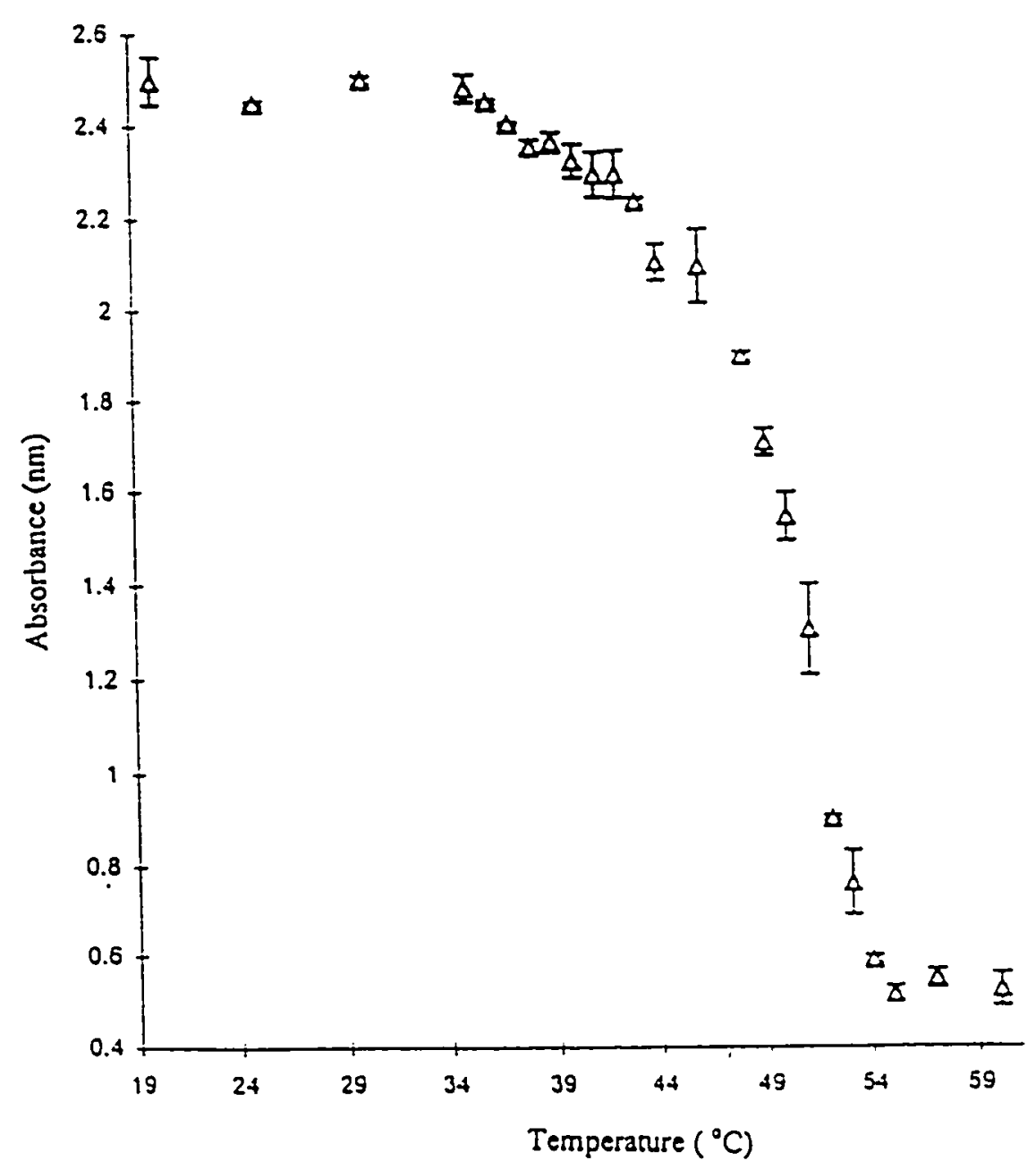

Figure 27: Thermal denaturation of $\mathrm{RNase} A$ at $\mathrm{pH} 4.50$ with the help of absorbance method. Conditions: buffer used $10 \mathrm{mM}$ acetate and $100 \mathrm{mM} \mathrm{KCl}, \mathrm{l}=57 \mathrm{~cm}, \mathrm{~L}=65.5$ $\mathrm{cm}$, capillary id $=50 \mu \mathrm{m}$. (The error bars represent standard deviation calculated for 7 experiments at each temperature.) 
absorbance appears bimodal with a transition midpoint of $38^{\circ} \mathrm{C}$ for the minor change and a transition midpoint of $51.4^{\circ} \mathrm{C}$ for the major change.

Figure 28 shows the electrophoretic mobility of RNase $A$ as a function of temperature. The results show a linear increase in mobility below $40{ }^{\circ} \mathrm{C}$ and above $54^{\circ} \mathrm{C}$. Since no change in the absorbance at $286 \mathrm{~nm}$ is observed in these regions it is assumed that the change in mobility is merely due to the decrease in viscosity associated with the increasing temperature. Between these temperatures, the mobility changes in two discrete steps. The mobility first levels off in the $40-45^{\circ} \mathrm{C}$ range and then increases markedly in one major step. Close inspection of the data reveals a midpoint of $48.3^{\circ} \mathrm{C}$ for this increase.

\subsubsection{Examination of the denaturation of RNase $A$ by the Taylor-Aris dispersion}

\section{method at pH 4.5}

The diffusion coefficient was measured over the entire temperature range used for the electrophoretic experiments and was converted to the frictional ratio $f / f_{0}$. The data shown in Figure 29 indicates an increase in the $f / f_{0}$ ratio with increasing temperature. The largest change is observed above $45^{\circ} \mathrm{C}$ range and appears bimodal. The lower temperature transition has a transition midpoint of $51.8^{\circ} \mathrm{C}$. The second step has an apparent midpoint near $57^{\circ} \mathrm{C}$. Since higher temperatures could not be examined, this value remains uncertain. 
Unfolding of RNase $A(\mathrm{pH} 4.5)$

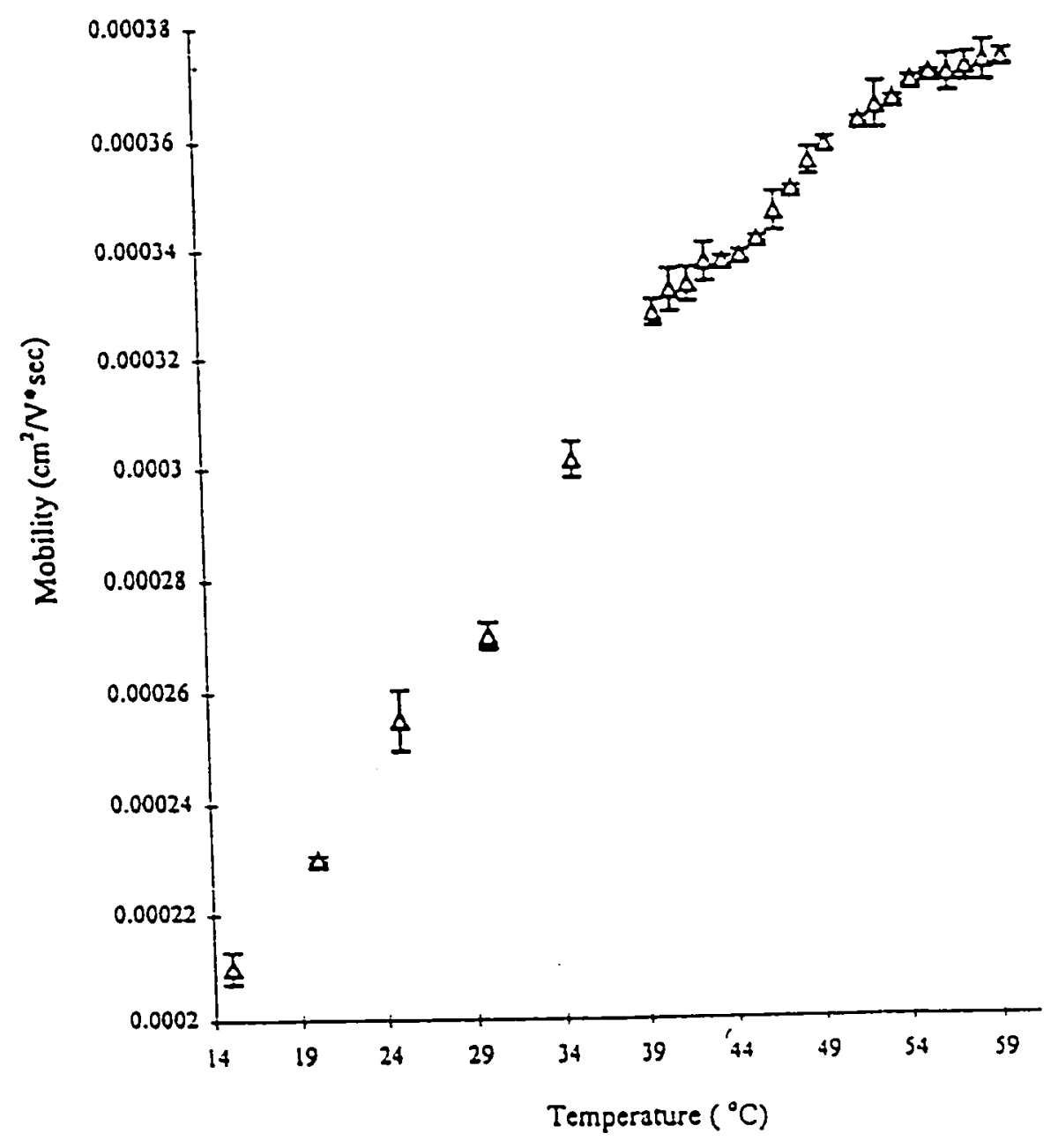

Figure 28: Thermal denaturation of $\mathrm{RNase} A$ at $\mathrm{pH} 4.50$ with the help of electrophoretic mobility. Conditions: buffer used $10 \mathrm{mM}$ acetate and $100 \mathrm{mM} \mathrm{KCl}, \mathrm{l}=57 \mathrm{~cm}, \mathrm{~L}=65.5$ $\mathrm{cm}$, capillary id $=50 \mu \mathrm{m}$. (The error bars represent standard deviation calculated for 7 experiments at each temperature.) 


\section{t/fo vs Temperature ( $\mathrm{pH} 4.5$ )}

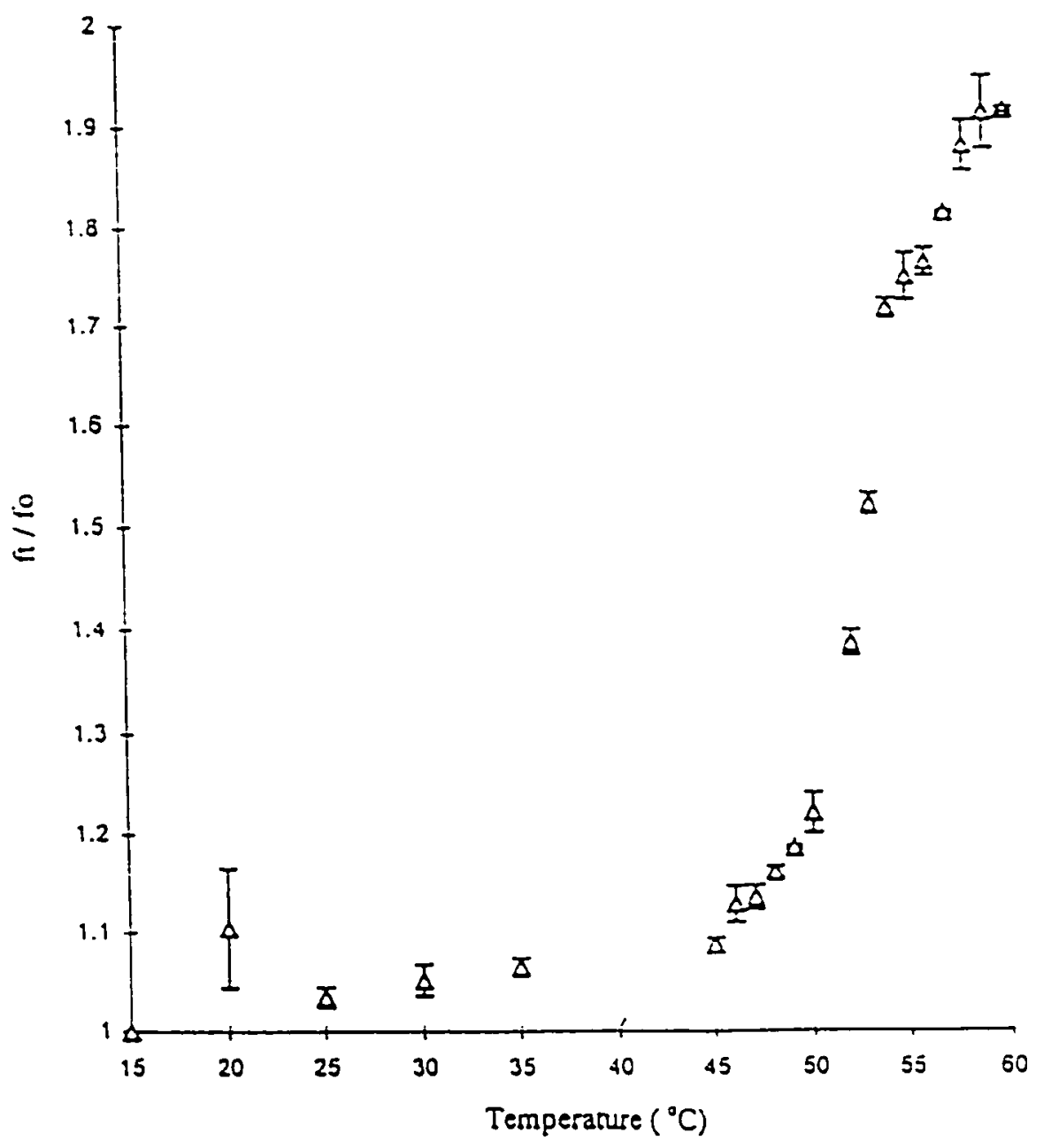

Figure 29: Thermal denaturation of $\mathrm{RNase} A$ at $\mathrm{pH} 4.50$ with the help of diffusion coefficient method. Conditions: buffer used $10 \mathrm{mM}$ acetate and $100 \mathrm{mM} \mathrm{KCl,} 1=57 \mathrm{~cm}$, $\mathrm{L}=65.5 \mathrm{~cm}$, capillary id $=50 \mu \mathrm{m}$. (The error bars represent standard deviation calculated for 7 experiments at each temperature.) 


\section{DISCUSSION}

\subsection{Electrophoresis studies}

Thermal denaturation is one of the important methods for studying the folding and unfolding of proteins, and is a direct measure of the stability of the protein in solution. Tanford et al. found that guanidine hydrochloride can denature a protein into a completely random coil form, whereas thermal and urea denaturations are less complete. 31

Since the electrophoretic mobility of a protein depends upon its conformation. electrophoresis is useful for studying the transitions between different conformational states. Unfolding is usually observed as an abrupt change in the protein's conformational properties. For many small globular proteins, there is a single unfolding transition. This indicates that only the fully folded $(N)$ and fully unfolded $(U)$ states can be populated under experimental conditions, that partially folded intermediates are unstable, and that the folding transition is cooperative with two states at equilibrium.

$$
N \Leftarrow \Rightarrow U
$$

This project involves the thermal denaturation of RNase $A$ as monitored by Capillary Zone Electrophoresis (CZE), absorbance and the Taylor-Aris diffusion method. The principle behind these techniques is described in the introduction. In short, the CZE experiment gives us knowledge about the electrophoretic mobility of the protein which is the ratio of charge to the radius of the protein. The absorbance sheds light on the environment surrounding the specific groups in the protein and the diffusion method allows us to know more about the hydrodynamic volume of the protein. As compared to 
conventional methods, the HPCE instument has many advantages including simplicity. rapid analysis and the requirement of a small volume of protein.

The $\mathrm{pH}$ values of 3.00 and 4.5 were chosen for the following reason. RNase A contains 10 Lys, 4 Arg, 4 His and 6 Tyr. It is a vary basic protein with the pi around 9.6. At a low $\mathrm{pH}$, the protein has a high positive charge. Pace et al. determined that at $\mathrm{pH} 3.00$ and $\mathrm{pH} 4.5$ native RNase $\mathrm{A}$ has +14 and +9 charges respectively. ${ }^{13}$ This charge difference will lead not only to a marked difference in the relative mobilities, but also a significant difference in the stability of $\mathrm{RNase} A$ at the respective $\mathrm{pH}$ conditions. Examination of such different conditions allows for an evaluation of the versatility of this technique.

The mobility is strongly dependent on the net charge on the protein as well as the viscosity and the hydrodynamic radius of the protein. If the charge on the native protein is the same as that on the unfolded protein then, by definition, the mobility should decrease as the hydrodynamic radius of the protein increases. In contrast to this, an increase in the mobility was observed, indicating that the unfolded state has a higher positive charge than the native state. These results are quite the opposite of those observed for the urea-induced denaturation of RNase $\mathrm{A}$ at $\mathrm{pH} 4$ using slab gel electrophoresis shown in Figure $30 .^{32}$ In this experiment, native RNase A (low urea) migrates at a faster rate than denatured RNase A (high urea). The reason for this difference may be due to the difference in the viscosities involved in the two experiments.

As discussed above, the native and denatured states of a protein may differ in both charge and hydrodynamic volume. Thus, the electrophoretic mobilities for the two states 


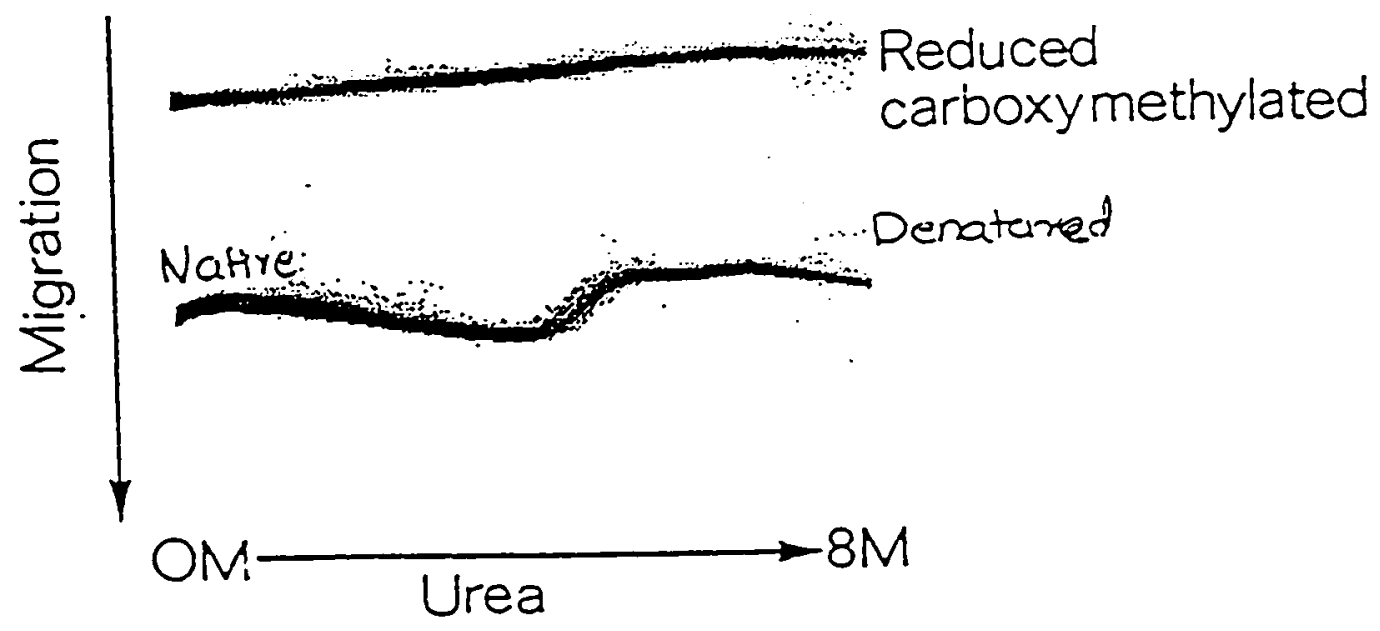

Figure 30: Urea-gradient gel electrophoresis of native and reduced carboxymethylated ribonuclease (reproduced with permission from Goldenberg, D. P.; Creighton, T. E. Anal. Biochem. 1984, 138, 1. () by the American Press). 
would differ, since mobility is a function of both these parameters. The extent to which charge and hydrodynamic volume contribute to the mobility depends on their relative magnitudes and the experimental conditions. In the CZE experiments presented here, the charge difference between the native and denatured states appears to dominate over the hydrodynamic volume difference. In the slab gel experiments, the higher concentrations of urea make the viscosity of the medium much higher than in the CZE experiments. Since viscosity affects the contribution of the hydrodynamic volume to the mobility and not the charge, it is plausible that a large enough difference in viscosity could make the hydrodynamic volume contribution the dominant term.

\subsection{Diffusion Results}

The Taylor-Aris diffusion method was applied to study the thermal denaturation of RNase $A$ and the diffusion coefficient $D$ was calculated for the native and the denatured protein. In order to check the validity of this method, the values of the diffusion coefficient were compared with those known from previous studies. Van Holde et al. used viscosity measurements to determine the value of the diffusion coefficient for native RNase $A$ at $\mathrm{pH} 7.7$ to be $1.23 \times 10^{-6} \mathrm{~cm}^{2} / \mathrm{sec}^{33}$ Our experiments gave comparable values of $1.13 \times 10^{-6} \mathrm{~cm}^{2} / \mathrm{sec}$ at $\mathrm{pH} 3.00$ and $1.26 \times 10^{-6} \mathrm{~cm}^{2} / \mathrm{sec}$ at $\mathrm{pH} 4.5$. Furthermore. the change in the diffusion coefficient was compared for the two $\mathrm{pH}$ vali.es to determine the degree to which the protein was unfolded at those $\mathrm{pH}$ values. The $\Delta D$ for $\mathrm{pH} 3.00$ was found to be $4.42 \times 10^{-7}$ and $4.85 \times 10^{-7}$ for $\mathrm{pH} 4.5$. This indicates that the protein has undergone similar changes at both $\mathrm{pH}$ values. Ginsberg et al. monitored the unfolding of 
RNase $\mathrm{A}$ at $\mathrm{pH} 2.1$ with viscosity measurements and found the intrinsic viscosity of denatured and native $\mathrm{RNase} A$ to be $9.08 \mathrm{~mL} / \mathrm{g}$ and $4.22 \mathrm{~mL} / \mathrm{g}$ respectively. ${ }^{14}$ The ratio of the intrinsic viscosities for the denatured to native protein is 2.15 . This value indicates the extent to which the protein is unfolded during denaturation. Bigelow et al. performed similar studies at $\mathrm{pH} 6.00$ and found the ratio of the intrinsic viscosities for the denatured and native states to be $1.97 .^{34}$ In our experiments, we used the values of the frictional coefficients instead of the intrinsic viscosities to study the denaturation of RNase A. The ratio of $\left[f_{U}\right] /\left[f_{N}\right]$ found to be 1.90 at $\mathrm{pH} 3.00$ and 1.91 at $\mathrm{pH} 4.5$ compares well with the other studies mentioned above. Bigelow et al. further pointed out that when RNase $A$ is denatured by using $8 \mathrm{M}$ urea or $6 \mathrm{M} \mathrm{GdnHCl}$ at $\mathrm{pH} 6.00$, the ratio of the intrinsic viscosities is 2.85 . This agrees with earlier studies and shows that thermal denaturation leads to a more compact structure as compared to the complete random coil in the case of $\mathrm{GdnHCl}$ and urea denaturation. 23

\subsection{Transition Midpoints Data}

Table II compares the transition midpoints obtained by various methods. The mobility data shows that at $\mathrm{pH} 3.00$, there is an indication of a pre-transitional event in the $35-40{ }^{\circ} \mathrm{C}$ range followed by the main transition at $43.7^{\circ} \mathrm{C}$. Furthermore, there is a small change in the mobility between $48{ }^{\circ} \mathrm{C}$ and $52{ }^{\circ} \mathrm{C}$ that could represent a posttransitional event. Traditional methods such as fluorescence and calorimetery show the midpoint of the transition to be around $45^{\circ} \mathrm{C}$. This agrees with the major mobility 
transition and the absorbance data which shows the transition midpoint at $45.1^{\circ} \mathrm{C}$. The major transition observed in the frictional coefficient data also shows a transition in this region with a midpoint of $43.3^{\circ} \mathrm{C}$. The second minor transition shows a midpoint at 48.5 ${ }^{\circ} \mathrm{C}$ that is similar to the putative posttransitional event observed in the mobility data. The absorbance data does not show pretransitional or posttransitional events. The lack of a pretransitional event in the absorbance data indicates that the tertiary structure changes that cause the mobility and frictional coefficient changes prior to the main transition are minor and have little effect on the environment about the tyrosine residues. The lack of a posttransitional event indicates that the tyrosine residues are fully solvent exposed after the main transition and further changes in structure do not affect their environment.

The results obtained at $\mathrm{pH} 4.50$ are similar to those obtained at $\mathrm{pH} 3.00$ with a few exceptions. First, the absorbance data is bimodal. The major transition has a midpoint similar to those observed for the frictional coefficient and electrophoretic data. The minor transition is comparable to the pretransitional event observed in the mobility data. Second, the electrophoretic mobility data does not show a posttransitional event, whereas the frictional coefficient data does.

The data obtained at both values of $\mathrm{pH}$ are consistent with a folding model involving twio intermediate states and are represented below as:

$$
N \Leftrightarrow I_{1} \Leftarrow I_{2} \Leftarrow U
$$

where $N$ and $U$ have their usual meanings and $I_{1}$ and $I_{2}$ represent the intermediates. The

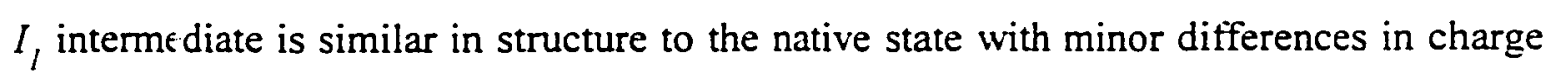


and hydrodynamic size. The transition from $I_{1}$ to $I_{2}$ involves the loss of the tertiary structure and thus $I_{2}$ is quite unfolded. The transition from $I_{2}$ to $U$ represents minor changes in structure. 


\section{CONCLUDING REMARKS}

This project has demonstrated that a CZE instrument is capable of following the thermal denaturation of proteins by absorbance, electrophoretic mobility, and through frictional coefficients. The resulting data compare well with published work. In addition. it has been shown that both electrophoretic mobility and frictional coefficient measurements provide a more sensitive measure of structural changes than absorbance spectroscopy does. The similarity of the data obtained for both values of $\mathrm{pH}$ suggest that these methods may be generally applicable to the study of protein folding. 


\section{REFERENCES}

1. Lehninger, A. L.; Nelson, D. L.; Cox, M. M. Principles of Biochemistry; Worth: New York, 1993; p 161.

2. Anfinsen, C. B. Science 1973, 181, 223.

3. Creighton, T. E. Protein Folding; W. H. Freeman: New York, 1992; p 238.

4. Creighton, T. E. Proteins Structure and Molecular properties; W. H. Freeman: New York, 1984; p 287.

5. Wetlaufer, D. B. Proc. Natl. Acad. Sci. USA 1973, 70, 697.

6. Harrison, S.C.; Durbin, R. Proc. Natl. Acad. Sci. USA 1985, 82, 4028.

7. Creighton, T. E. Biochem. J. 1990, 270, 1.

8. Dill, K. A. Biochemistry, 1990, 29, 7133.

9. Swindell, M. B. Protein Science 1995, 4, 93.

10. Brandts, J. F.; Lin, L. Biochemistry 1990, 29, 6927.

11. Heiger, D. N. High Performance Capillary Electrophoresis; Hewlett- Packard: France, 1992; pp 6, 15, 17, 19, 28, 29, 30, 36 .

12. Creighton, T. E.; Goldenberg, D. P. J. Mol. Biol. 1984, 179, 497.

13. Pace, C. N.; Laurents, D. V.; Thomson, J. A. Biochemistry 1990. 29, 2564.

14. Ginsberg, A.; Carroll, W. R. Biochemistry 1965, 4, 2159.

15. Ghuman, R.; Henriquez, V.; Biringer, R. G. San Jose State University, unpublished results.

16. McCormik, R. M. Anal. Chem. 1988, 60, 2322.

17. Jorgenson, J. W.; Lukacs, K. D. J. High. Res. Chromotogr. 1985, 8, 407. 
18. Jorgenson, J. W.; Lukacs, K. D. Anal. Chem. 1981, 53, 1298.

19. Lambert, W. J.; Middleton, D. L. Anal. Chem. 1990, 63, 1346.

20. Lukacs, K. D.; Jorgenson, J. W. Science 1983, 222, 266.

21. Rush, R. S.; Cohen, A. S.; Karger, R. M. Anal. Chem. 1991, 63, 1346.

22. Hilser, V. J.; Worosila, G. D.; Freire, E. Anal. Biochem. 1993, 208, 125.

23. Van Holde, K. E. Physical Biochemistry, Prentice Hall: New Jersey, 1985; pp I38139.

24. Tanford, C.; Hauenstein, J. D. Biochemistry 1956, 78, 5287

25. Boumia, A.; Coull, J.; Houghton, G. Proc. Roy. Soc. A 1956, 235, 67.

26. Taylor, S. G. Proc. Roy. Soc. A 1953, 219, 186.

27. Taylor, S. G. Proc. Roy. Soc. A 1954a, 223, 446.

28. Taylor, S. G. Proc. Roy. Soc. A 1953, 225, 473.

29. Bello, M. S.; Rezzonico, Roberta.; Righetti, P. G. Science 1994, 266, 773.

30. Grossman, P. D.; Soane, D. S. Anal. Chem. 1990, 62, 1592.

31. Bringer, R. G.; Fink, A. L. J. Mol. Biol. 1982, 22, 381.

32. Goldenberg, D. P.; Creighton, T. E. Anal. Biochem. 1984, 138, 1.

33. Van Holde; Boldvin. Biochem. 1958, 62, 734.

34. Bigelow, C. C. J. Mol. Biol. 1964, 8, 696.

35. Herman, J.; Scheraga, H. A. J. Am. Chem. Soc. 1961, 83, 3283. 
Author: DAVID HEIGER at hp-littlefalls, oml Date: $\quad 09 / 20 / 96 \quad 05: 57$ AM

Priority: Normal

TO: SHARMIIA UDIAVAR at HP-PalOAIto, om16

CC: DAVID HEIGER at HP-LittleFalis, OmI

Subject: Re :

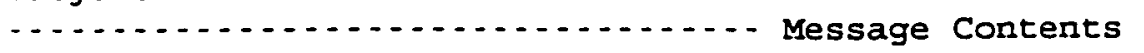

Hello Sharmila,

Please feel free to use the sited literature in your thesis.

Regards,

David

Subject:

Reply Separator

Author: SHARMILA UDIAVAR at HP-PaIOAlto, om16

Date: $9 / 11 / 9616: 03$

Hi David,

My name is Sharmila Udiavar. I an currently working as a seed in HP Palo Alto,California. I am a graduate student at San Jose state University, San Jose- CA, finishing up with M.S. in chemistry. I want to include few figures (figure 1, 5, 8, 12, 13, 14 and 19 ) from the Book entitled "High Performance Capillaty Electrophoresis (An introduction)" in my M.S. thesis. I would like to let you know that three copies of my thesis would be published. I would like to receive a written permission /an E-mail from you in this regard.

With regards,

Yours truly,

Sharmila Udiavar 